\title{
Identifying the Sources of Technological Novelty in the Process of Invention
}

\section{May 17, 2015}

Abstract. Much work on technological change agrees that the combination of new and existing technological capabilities is one of the principal sources of inventive novelty, and that there have been instances in history when new inventions appear with few antecedents. The many discussions across research communities regarding the relative roles of combination and origination as sources of technological novelty have not provided much in the way of formal identification and quantification. By taking advantage of the technology codes used by the U.S. Patent Office to classify patents, we discretize technologies and identify four distinct sources of technological novelty. The resulting technological novelty taxonomy is then used to assess the relative importance of refining existing technologies, combining existing and new technologies, and de novo creation of technological capabilities as sources of new inventions. Our results clearly show that the process of invention has been primarily a combinatorial process accompanied by rare occurrences of technological origination. The importance of reusing existing technological capabilities to generate inventions has been steadily rising and recently overtook recombination as the source of novelty for most new inventions.

Keywords: patent technology codes, technological novelty, combination, origination

*: Corresponding author. ASU - Santa Fe Institute Center for Biosocial Complex Systems, Arizona State University, Tempe, AZ 85281 USA. Phone: (480) 727-2029. 


\section{Introduction}

Three perspectives dominate the discussion about the sources of novelty in invention technological change. Many researchers studying invention agree that combinations of new and existing technological capabilities are a principal source of inventive novelty. Under this combinatorial view of technological change new technologies are constructed from existing technologies, which in turn become available as building blocks in the construction of other new technologies (see, for example, Auerswald et al., 2000; Basalla, 1988; Fleming and Sorenson, 2004; Hargadon and Sutton, 1997; Henderson and Clark, 1990; Levinthal, 1997; Ogburn, 1950; Rosenberg, 1982; Usher, 1954; Von Hippel, 1988; Weitzman, 1998). A second, prominent perspective of human technological development, taking the long-view from the time of huntergatherer societies to the present, has been gradualism - the slow accumulation of variations and improvements in the features of tools and technologies, the result of both deliberate modifications and accidental tinkering (Boyd et al. 2011; Mott, 1997; Pacey, 1990; Purcell, 1982; Richerson and Boyd, 2005; Russo, 2004). A third body of research points to instances of new technologies appearing with few antecedents that originate technological pathways rather than extend existing ones (Arthur, 2009; Christensen, 1997).

The many discussions about the processes underlying technological development, and the relative roles of combination and origination as sources of technological novelty, have not provided much by way of quantification. The paucity of formalization is not surprising given the difficulties in discretizing technologies and classifying technological novelty systematically across a broad set of technologies. Here we present a taxonomy of inventive novelty (as instantiated in patented inventions) based on how the U.S. Patent Office classifies the technological novelty of patents. We use this taxonomy to quantify the relative proportion of 
inventions that originate new technological capabilities, combine new or existing technologies in novel ways, or reuse existing capabilities as sources of inventive novelty. As McNamee (2013) reminds us, taxonomies—used to categorize and differentiate entities based on relevant criteriaare crucial in efforts aimed at understanding complex phenomena. ${ }^{1}$ The taxonomy we have developed can be used to non-arbitrarily distinguish significant improvements from incremental ones in inventive activity, a subject of long-standing interest and debate (see, for example, Freeman and Soete (1997)).

Patented inventions are one manifestation technological novelty, and what is novel about an invention is described by its inventors, in precise, technical detail, in a patent's claims. ${ }^{2}$ The United States Patent and Trademark Office (USPTO) classify inventions by encoding information contained in the claims using a system of numerical codes, the patent technology codes. At any given time, the existing set of technology codes available to a patent examiner is essentially a description of the current set of technological capabilities. With each new patent application a patent examiner must decide which existing codes to use to capture the technological components responsible for the patent's novelty, and whether or not new technology codes are required to capture the invention's newness. The introduction of a new technology code sets in motion a retroactive reclassification of all previous patents that may have embodied the newly recognized technological capability. The Patent Office's technology codes thus constitute a set of consistent definitions of technological capabilities spanning over 200

\footnotetext{
${ }^{1}$ The scientific study of organisms and biological systems can be dated to the introduction of the Linnaean taxonomy in 1735. As there is still no widely accepted technological taxonomy the study of technological change is in a sense still in a pre-Linnaean state.

${ }^{2}$ A patent however does not identify precisely what is novel about the invention, nor are inventors legally required to clearly highlight in the claims (which legally define the patent) where the novelty of the invention lies (Lemley, 2011).
} 
years of inventive activity. The technology codes are the crucial empirical ingredient in the construction of our taxonomy of inventive novelty.

The discussion is organized as follows. The next section sets the conceptual framework and poses the research questions. Section three describes the use of patent technology codes to classify the technologies embodied in patented inventions. Section four develops the taxonomy of technological novelty and presents the main empirical results, among them the relationship between the types of inventive novelty constituting the proposed taxonomy and the citations profile of these novelty types. In section five the validity, or perhaps more accurately, the sensibleness, of the novelty taxonomy is assessed through an examination of how the taxonomy classifies a set of historically and economically significant patents. Section six concludes.

\section{Conceptual Framework and Data}

\subsection{Research Questions}

What is a technology? According to Romer (2010) technologies are ideas about how to re-arrange matter, energy and information; for Arthur (2007) technologies are means to fulfill a human need or purpose. In the present discussion we similarly define technologies as functionalities_artifacts, devices, methods, and materials_available to humans to accomplish specific tasks. An invention is a unique or novel device, method, composition or process. Distinct from technology, an invention integrates distinct technological functionalities. It is important to note that technological novelty is not the same as inventive novelty. Technological novelty arises, and technological change occurs, when new technological functionalities are introduced into the existing repertoire of technologies. Inventive novelty - new artifacts, devices, processes, materials or compounds - may not necessarily embody technological novelty. 
The technology codes used by the Patent Office as identifiers of distinct technological functionalities makes it possible to describe, and rank, inventive novelty as resulting from the development of new technological capabilities, the combination of technological capabilities in ways that had not been previously witnessed in the patenting record, or from the reuse of technologies. Using the technology codes for empirical support, we address the following specific research questions:

Q1. What are the sources of inventive novelty (as revealed through patents)?

Q2. What roles have combination and refinement played in the development of new inventions?

Q3. Have the rates at which the various sources of technological novelty arise been changing over time?

Q4. In the case of patented inventions whose novelty resides in the novel combination of technological functionalities, how similar or dissimilar are the technologies brought together?

Perhaps the most pressing and obvious question, namely whether the taxonomy is meaningful, valid and/or sensible, is the most difficult to answer directly. A measure of validity would seem to be inherited from the taxonomy's reliance on the Patent Office's mandate practice of identifying the technologies responsible for an invention's novelty. We inquire as to the relationship between forward citations, a common indicator of a patent's importance or influence, and the different types of inventive novelty identified by our taxonomy. And we also classify over one hundred "significant" patents, whose significance has been attested by historians and experts, using the taxonomy presented here. But we readily acknowledge that we 
do not have an independent validation of how meaningful the taxonomy is. How useful the taxonomy is will be validated through use by the research community.

\subsection{Patent Data and Technology Codes}

U.S. Patent Law specifies four categories of inventions or discoveries that are eligible for the protection of a patent: processes, machines, manufactures and compositions of matter. Additionally, the U.S. Supreme Court has reaffirmed the patentability of business methods, computer programs and mathematical algorithms (561 U.S. Supreme Court, 2010). The United States Patent and Trademark Office (USPTO) grants three types of patents: utility patents (also referred to as "a patents for invention") which are issued for the invention of "new and useful" processes, machines, artifacts, or compositions of matter; design patents, which are granted for the ornamental design of a functional item; and plant patents which are conferred for new varieties of plants or seeds (over $90 \%$ of the patents granted since 1790 by the USPTO are utility patents). U.S. patents therefore encompass a very broad array of technologies and the taxonomy presented here takes full advantage of this diversity.

A patent is intended to be limited to only one invention consisting of several closely related and indivisible (i.e. integrated) technologies that, acting together, accomplish a specified task (in patent law this is known as the "unity of invention"). In simple terms, this means is that a jet engine cannot be patented, but the numerous individual components that constitute a jet engine can. The Wright Brother's 1906 patent for a "flying machine”, for example, is actually for a method of controlling the direction and altitude of a flying device, not for the concept of an airplane. In the case of inventions which accomplish multiple and separable tasks the inventors can be required to file separate patent applications for each distinct task or component. 
What an invention is and what it does is described by a patent's authors in the numbered claims which also serve to define the scope of the legal protection granted by the patent. The USPTO uses a system of technology (or classification) codes to identify and classify the technologies invoked by approved claims which embody the invention's novelty. The codes constitute a classification system that groups patents together according to similarly claimed subject matter (allowing for patents to be searchable), and are used by patent examiners when searching for relevant prior art during a patent application examination process. The classification system is constitutionally mandated to provide an exhaustive reference to all patentable subject matter; the present USPTO patent classification system is based on the general structure of the first classification schema created in 1900. (We hasten to clarify that the codes assigned to a patent do not provide a list of all of the technologies utilized by the invention but only those responsible for the invention's novelty.)

A technology (or classification) code consists of two components: a technology class and a technology subclass. Classes are major categories of patentable technology while subclasses delineate processes, structural features and functional specifications of the class. Subclasses have very detailed definitions and some subclasses are nested within hierarchical relationships to other subclasses. There are currently 474 classes and about 25,000 subclasses that are combined by the USPTO to create over 160,000 unique technology codes.

Just as the minimum criterion for obtaining a patent is a single claim of novelty, a patent must be classified by at least one code, but there are no limits to how many codes may be assigned to a patent. There is no specified relation between the number of claims and the number of technology codes used to classify a patent although one code, the "original" or "primary" classification code does correspond to the controlling claim. Other than the original 
classification, the order of technology codes in a patent is arbitrary. The passage from claims to codes is a well-defined and highly codified procedure, but nonetheless depends on the experience of the patent examiners. The reduction of the number of claims to a more limited number of codes is not informative or revealing about the nature of the technologies constituting an invention. (For a more detailed discussion of the role of claims in a patent and how technology codes codify claims see Strumsky, Lobo and van der Leeuw (2010).) Once the classification is completed a patent's classifying codes encapsulate those aspects of novelty set forth in the claims. We refer to the set of $n$ technology codes classifying a patent's technological novelty as an $n$-tuple. (For the results presented here n-tuples are treated as combinations and not as permutations.)

"Classification orders," issued monthly by the USPTO, record the changes made to the classification system over the previous month. Classification orders convey the abolishment, reclassification and (very infrequently) introduction of technology codes. The recognition that a new technological capability has come into existence is formalized by the introduction of a new technology code, and usually occurs after the new capability has been in play. When the set of technology codes is revised, the USPTO reviews all granted patents and reclassifies those meeting the criteria of the new codes. As an example of this back-dating process, consider the case of nanotechnology. In October 2004 the USPTO announced the creation of a new technology class, Class 977, for nanotechnology. The USPTO then reviewed patents issued before the 977 class was created and re-classified those meeting the 977 criteria; as a result, according to the USPTO the first patent characterized as embodying nanotechnology was file in 1972 and granted in 1975. As a consequence of the reclassification process, technology codes provide a consistent classification scheme making it possible to compare patent technologies 
across more than 200 years of inventive activity for nearly all patentable technologies. The research reported on here relies on the technology codes as marking individual technological capabilities and on the accumulation of codes providing temporally consistent identification of a repertoire of technologies.

\section{3. $\underline{\text { Basic Empirics }}$}

We now present some basic empirics for technology codes and the technology $n$-tuples. We use data on all three types of patents together with data on defensive publications and statutory invention registrations, and assign them according to the year each patent was applied for - the application year-so as to count patents as close as possible to the time they were invented. ${ }^{3}$ To dampen noise, time-series results are presented for five year windows starting in 1830 and ending in May 2014. The year 1830 was chosen as the starting date on the plots and graph due to the paucity of patent observations from 1790 to 1839 ; however the calculation include all patents in the data back to 1790. (Construction of the patent database is discussed in Appendix A.)

Figure 1 shows various percentiles of technology codes counts (calculated within each five-year window). The mean number of codes categorizing patents has increased over 180 years, a reflection of the steadily growing technological complexity of inventions. There has been far less change at the bottom of the distribution, whereas since 1925 the top $25 \%$ began to diverge in their mean number of codes. Prior to 1925 the mean and the median number of codes hovered around 2 and have only risen to about 3 ; however the $95^{\text {th }}$ and 75 th percentiles have

\footnotetext{
3 "Defensive publications" and "statutory invention registrations" have been used as instruments of intellectual property strategy by patent applicants who believe their applications will not be successful or that their inventions will not be economically viable. By publishing these documents applicants ensure their inventions are in the public domain and competitors cannot subsequently patent them.
} 
risen steadily since the late 1800 's from 2 and 4 respectively. Currently the $75^{\text {th }}$ percentile is between 4 and 5 and the $95^{\text {th }}$ percentile has shot up to between 9 and 10. Figure 2 shows the distribution of patents by $n$-tuples for all patents granted between 1830 and 2014. Over 64\% of all patents have been categorized by applying no more than three technology codes, and four codes have sufficed to describe over $75 \%$ of all patents granted covered by the dataset.

The increase in the mean and median number of codes classifying patents has been much slower than that of patenting itself: the annual rate of increase in the average number of codes used to describe an invention has grown by less than 1\%, from 1975 to 2005, while the number of granted patents increased by slightly over $3 \%$ a year over the same period. Patent examiners, guided by the "unity of invention" principle have been parsimonious in encoding inventions, despite having more codes available to describe the inventions. The codes provide a precise and concise vocabulary for describing the novelty of inventions.

Figure 3 depicts the change over time for the proportion of patents categorized by different $n$-tuples (the percentages are calculated over five-year windows). Whereas one technology code is enough to categorize over $60 \%$ of patents granted between 1830 and 1870, by 2000 only $15 \%$ of patents could be described as having only one technological functionality (although this has been rising in recent years). On average, over the past 50 years over a quarter of all inventions have required 5 or more codes indicating that a significant portion of inventive activity consists of combining several distinct technologies. Figure 4 shows the percentage of differently sized $n$-tuples which are unique, that is, have been used only once to categorize a patent over the period 1830 to 2014 . Over $75 \%$ of code combinations consisting of just two codes (2-tuples) have only been used once; in the case of 3-tuples it's over 90\% and for 4-tuples 
and higher it is an astounding $95 \%$ or more. The unique usage of the $n$-tuples is further evidence that the codes are indeed very precise descriptions of technologies embodied in inventions.

\section{Identifying and Quantifying the Sources of Inventive Novelty}

\subsection{A Taxonomy of Inventive Novelty}

Since technology codes denote specific technological capabilities, multiple codes are often combined by patent examiners in order to describe the technologies responsible for a patented invention's novelty. In building our taxonomy we focus on the pairings (binary combinations) of capabilities which can be generated from an $n$-tuple-pairings which are inherent in the interactions among the technologies which constitute an invention-and use these pairings to assess inventions' technological novelty. We explain the procedure with a stylized example.

Consider a patent categorized by a 3-tuple, $\{\mathrm{a}, \mathrm{b}, \mathrm{c}\}$, with $\mathrm{a}, \mathrm{b}$ and $\mathrm{c}$ denoting three technological capabilities. This 3-tuple generates the following pairings of technologies: ab, ac, and bc (recall that the order in which technology codes are arranged in an n-tuple does not matter). If the three codes used in the 3-tuple are new (that is, have not been used before to categorize any patent), the invention is considered to be original. If $\mathrm{a}$ and $\mathrm{b}$ have already been observed together on a patent, while $\mathrm{c}$ is a new code (thus the pairings ac and bc will be new), then the invention is labeled a novel combination. If all the three codes have been used before to categorize patents, and if the paring ac has not been used in a patent before whereas the pairings ab and ac have, the 3-tuple is classified as a combination. If the three codes have been used before and all three pairings have occurred previously in patents, the 3-tuple is labeled a refinement. Pairwise combinations prevent the following mischaracterization that occurs when using full $n$-tuples. Assume at time $t=0$ the 3 -tuple a, b, c is observed for the first time (thus all 
the pairs $a b, a c, b c$ are observed together at time $t=0$ ) and is labelled a new combination. In the following period, $t=1$, the pair a, $\mathrm{b}$ is observed, by implementing a pairwise combination rule we acknowledge that the pair ab have already been combined. If a full $n$-tuple rule were imposed then the pair ab observed in period $t=1$ would be considered a new combination despite having been observed together previously.

The following definitions specify the ways in which we use patents' technology codesused by the Patent Office to identify and classify technological novelty - to identify different sources of technological novelty and categorize a patent's inventive novelty.

1 Origination: all the codes used in the classifying $n$-tuple are new (meaning they have not been used before in the patent record).

2. Novel Combination: the $n$-tuple consists of new binary combinations with at least one new code ("new" meaning that it had not been used before in the classification of patents).

3. Combination: the n-tuple consists of new pairwise combinations of technological capabilities used in previous patents ("new" means not used in a previous period to classify an invention).4. Refinement: all of the codes used to classify a patent have been used in previous patent descriptions, and the binary pairings have all been used previously to categorize patents.

Each of definition aligns with one of the dominant perspectives on sources of technological novelty in invention. Combination and novel combination as defined here is close to the notion of technological combinatorics often found in the literature (e.g., Fleming, 2001). Refinement (or reuse) involves the grouping of previously existing capabilities or functionalities - we clarify that we do not here use the term as normally employed in engineering to refer to slight modifications of existing designs or blueprints. On the contrary, the novelty of two inventions might be described using the same set of technology codes but depending upon 
what other non-novelty-inducing technologies the novelty-inducing technologies are combined can result in very different artifacts and or processes. Conditional on what other technologies those responsible for the invention's novelty are packaged with, the ensuing invention might constitute a significant contribution to the inventive record.

Originations and novel combinations are the two types of inventions which involve not only combining technologies in ways not seen before but also the use technologies not previously in existence - these two types of inventions can be considered as being the most novel. (Appendix B provides examples of patents which illustrate the four sources of technological novelty.) For the whole of the patent record, refinements represent about $56 \%$ of inventions, while combinations account for 42\%; novel combinations and originations each constitute less than $1 \%$ of all inventions. Since 1800 the growth in the total number of codes and total number of patents has been exponential, and closely matched each other until about 1870 . Since 1870 the growth rate of the repertoire of codes has slowed down considerably (the relationship between levels of patenting activity and the number of technology codes is discussed at length in Youn et al. (2014)).

One difference among patents classified using the above taxonomy which can itself be an indicator of differentiated novelty is in their number of claims. From 1960 (the earliest year for which we have a comprehensive electronic file of claims per patent) to 2013, the mean number of claims for originations is 7,12 for novel combinations, 13 for combinations 14 for refinements. An ANOVA results indicate the mean number of claims for each of the four taxonomy groups are statistically significantly different at the $99 \%$ confidence level, and multiple tests for pairwise comparisons confirm each group to be different from one another at the $99 \%$ confidence level. Clearly originations are characterized by having fewer claims. One 
would expect originations and novel combinations to have fewer claims than combinations or refinements, as there is likely to be less prior art crowding the legal territory for patentable inventions in those types of technology. More mature technologies with a large body of existing patents and prior art will, on average, require more claims of narrower scope. This is consistent and confirmed by the statistical difference in the means and the lower average number of claims of originations and novel combinations. The relationship between the number of claims and the number of codes on a patent is very weak: over the period 1960 to 2012 the correlation between the number of codes and the number of claims is only 0.14. A preponderance of claims are dependent claims, that is, claims reference another claim and are proper subsets of their parents claim. A particularly large number of claims is neither indicative of the complexity or breadth of a patent as only a single claim may be independent (Lerner, 1994).

We now present our main empirical results. Figure 5 shows the time series (expressed in natural logarithms for ease of comparison) for the number of total patents and totals for each source of new patents (data show for five-year windows by application year). Several features stand out, most important is that the majority of patented inventions consist of combinations and refinements. These two sources of technological novelty have fueled the increase in invention observed over the past three decades. Refinements, more than combinations, were the major source of invention up until the 1930's, from 1940 until 1990 combinations dominated, but only slightly, before losing their dominant position again. From 1980 to 2014, combinations and refinements accounted for $47 \%$ and $52 \%$ of all patents, respectively.

Figure 6, shows the number of patents granted in each taxonomical category, zooms in on the period between 1950 and 2010, making it easier to note the remarkably steady rate at which new technological capabilities (referred to as originations in our taxonomy), were introduced 
after 1950. The burst in originations that occurred between 1980 and 1990 was likely due to an increase in patenting in drugs and biotechnology. Figure 7 shows the percentage of patents for each category (per 5 year time-window). Since the mid 1800's refinement was the primary source of invention-representing around 60\% of all new inventions until 1940. Between 1940 and 1990, combinations drove the invention process, and after 1990 refinements dominate once more. From 1900 to 2014, the role of new technological capabilities, either as originations or novel combinations, as a source of new inventions was quite minimal, accounting for less than $1 \%$ of patents. Despite a substantial decline as a share of overall invention, the rate of creation of new technological capabilities remained relatively stable over a period of time that saw dramatic transformations in economy and society. These patterns are not an artifact of aggregating patents across industries and technologies: the same patterns are observed when patents are grouped into 56 technology areas (such as communications, drugs, optics, medical devices, etc.). ${ }^{4}$ Even software patents-the very embodiment of modern technology and the dematerialization of technology—exhibits the same overall time dynamics: technological refinements are by far the most prevalent type of new inventions.

The diminished role of new individual technologies as a driver of technological change is further clarified by using the original classifications (OR) codes as a probe into the nature of technological novelty in patented inventions. We remind the reader that OR codes describe the most important information contained in a patent - the technical and scientific information disclosed in the patent's claims that supports the examiner's determination that the invention is new and non-obvious. If an OR code is new (i.e., has not been used before in classification), it signifies that the invention itself defines a new technological capability. If a patent represents an

\footnotetext{
${ }^{4}$ These results are available upon request.
} 
origination, then by definition its OR code denotes a new technological functionality; however if a patent is a novel combination, then its new code does not necessarily play the OR role. Figure 8 shows the percentage of new patents, per 5-year window, already classified as an origination or novel combination in which one of the new codes is also an OR code. This percentage has declined from about $100 \%$ in the early 1800 's to slightly above $30 \%$ since the year 2005 . New technologies are much more likely to arrive as a new feature of characteristic of an existing technology, rather than on its own as an origination. While this might reflect the increasing complexity of inventions it could also point to a shift away from the development of new technological functionalities as the centerpiece of the invention process.

\subsection{Invention as Combinations: Deep or Broad?}

The number of component technologies in patented inventions classified as "combinations" and "novel combinations" is higher than for originations or refinements. Of all patents successfully applied for from 1900 through 2014, novel combinations and combinations have a mean number of 5 technology codes, in contrast to originations with a mean of 3 and refinements with a mean of 2 . This would seem to imply combinations and novel combinations are more combinatorial in nature; however, what if most of what is combined is actually quite similar? An important distinction to be made is that between deep technological combinationsmeaning that the technology codes classifying a patent are all within a specialization and therefore "similar" to each other-and broad combinations-meaning that the combined technology codes are more "distant" in subject matter. The USPTO technology code definitions are organized as a tree-like network topology, each of the 474 classes define a root with hierarchical branches formed by the subclasses, with branching factors as low as 2 or as high as 15. When two codes appear on a patent from the same class, that is the same tree, we consider 
the combination deep, when the technologies codes are from two different trees (ie. classes) we consider the combination broad. Calculating average distance across technology classes is problematic as the classes are not ordered or connected, thus form 474 distinct trees. We do not expand further on the tree-like network structure, and draw the distinction between technology codes on a patent as coming from the same class or from different classes.

Figure 9 shows the percentage of the four technological novelty classifications involving codes all drawn from the same class. A substantial portion of the combinatorics of technological change is driven by the granularity of the subclasses. Even though codes denote distinct technological capabilities, codes sharing a technology class can be very similar in their functionality. Over $70 \%$ of all refinements involve a single technology class, meaning invention in refinements primarily involve combining on average 2 very similar technologies from within the same technology class. Originations have exhibited the most change, starting from $100 \%$ of originating patents encoded within a single technology class, falling to less than half of originating patents characterized by technologies with single class. Originations and refinements are both driven by "deep" recombination of related technologies. Combinations and novel combinations are driven by a process of broad recombination, bringing together, both, more technologies (on average 5) and more diverse technological capabilities. Since the 1860's, all categories demonstrate a similar trajectory in which technological novelty is increasingly generated by an inventive process that combines more diverse capabilities, but combinations have done so more dramatically than the other 3 categories.

Figure 10 shows the average technology class Herfindahl index calculated for each patent based on the technology classes associated with each code that appears on that patent. Starting in 1830, the Herfindahl index for each patent is averaged across all patents in that 5 year time 
window (based each patent's application year) for the four technological novelty classifications. The high average Herfindahl is expected given the results shown in figures 3 and 8; however the difference between Originations and Refinements on one hand and Combinations and Novel Combinations on the other is stark. The steady decline in the value of the average Herfindahl index from 1865 to 1955 illustrates the increasing breadth of the combinatorial process; whereas the upward trend from 1955 onwards may reflect the shift towards invention in industries such as electronics and computers that are characterized by a more "deep" combinatorial process than a "broad" one.

\subsection{Technological Novelty and Citations}

What insights does the taxonomy of novelty presented here provide that is not captured through patent citations? A few comments are in order regarding the key analytic differences between using citations and technology codes. Given the importance of citing prior work in the academic peer-reviewed literature, an experience familiar most researchers, it is understandably tempting to equate the role of citations in papers and that of citations in patents. It is vitally important to remember that patent citations serve a specific legal function; whereas citations in scientific literature indicate intellectual influence and lineage. Citations to prior patents are made to delineate a patent's claims of inventive originality and bound the scope of legal protection sought by the proposed invention. If patent $\mathrm{B}$ cites patent $\mathrm{A}$ in its prior art this implies that one of the claims made by the authors of patent B builds upon some claim contained in patent A; prior art citations are not meant to indicate which technological capabilities contained in a new invention are utilized by a prior invention. ${ }^{5}$ It is possible an inventor was not even aware of a

\footnotetext{
5 This is implicitly assumed by efforts such as Rosenkopf and Nerkar (2001) which use citationbased measures to determine the degree to which inventions span both technological and
} 
particular technology included in a patent's prior art. Over one third of all prior art citations on patents granted since 1965 are included by the examiners, not the inventors, leaving ambiguity in the conceptual lineage and knowledge flow interpretations of prior art citations metrics. However, patent citations do provide evidence of an invention's successful progression to an innovation in the technological change process. Citations effectually measure an inventions usefulness and successful diffusion (Albert et al., 1991; Hall, 2005).

What is the citation profile of patents classified according to their sources of technological novelty? The correlation between the number of codes and citations received is only 0.06 (for the 1975 - 2010 period). We compiled the number of citations accrued by a patent, and to allow for fair comparisons only citations received within eight years of the grant date were counted since patents receive the bulk of their citations within eight years of being granted (Hall, Jaffe and Trajtenberg, 2001). For patents with grant years between 1975 and 2005, the mean and median citation counts are 7.9 and 3, respectively, for originations, 35.9 and 15 for novel combinations, 15.8 and 7 for combinations and for refinements, 12 and 5. There is essentially no difference between combinations and refinements with regards to how often these types of patents are cited which is somewhat surprising as one might expect a higher level of citations for combination patents since they combine several technologies.

Different technology groups (captured through the technology classes) have different citation rates. It is therefore useful, to facilitate a more informative comparison, to normalize citations counts by the patent grant year and by technology class. To accomplish this, we assigned every patent to a technology class based on the class of its primary technology code. The mean and variance of forward citations was then calculated for every technology class per

organizational boundaries, or Dahlin and Behrens (2005) who use citations attempts to measure the radicalness of innovation. 
grant year, and then a z-score value was generated for the citations received by each patent. Figure 11 shows the average normalized citations rates for the four types of technological novelty. Even when normalized the same result holds: novel combination patents are cited more often, by several orders of magnitude. (This result is maintained when the time window for accumulating citations is $3,5,20$ and 25 years). Interestingly, this patent result is similar to that reported by Uzzi et al. (2013) for scientific papers-they find that the most highly cited (and presumably more influential) papers represent a combination of the new and well established science.

Is the technological novelty of a patent, as defined here, reflected in the number of prior art citations? It would seem reasonable to expect that patents classified as "originations" and "novel combinations" under the taxonomy presented here, being that they are more novel and more likely to break new technological ground, should have fewer prior art citations. Whereas only about $3.5 \%$ of all patents successfully applied for since 1975 are devoid of prior art citations, the percentage of origination patents that cite no prior art is $41 \%$. The mean and the median prior art citations for originations are 4.7 and 3 respectively; 6.9 and 5 for novel combinations, 11.7 and 7 for combinations, and 13.5 and 6 for refinements. The differences in mean prior art citations rates are significant at the 99\% confidence level based on an ANOVA test, as are the pairwise comparisons of means by classification type (the ANOVA result is sustained under the same normalization implemented with forward citations, normalizing by each patents $O R$ technology class and application year). This is further evidence that originations capture more technologically novel inventions that rely less on existing technologies.

The two most two widely used patent citation-based measures are "originality" and "generality" (Hall et al., 2001). Recall that "originality" is intended to capture whether a patent's 
prior-art citations are drawn from a broad or narrow set of technology classes, and "generality" captures whether a patent's forward citations are confined, or not, to a narrow set of technology classes. We calculated every patent's originality measure for patents successfully applied for between 1975 and 2013; the mean and median values for the originality measure are remarkably the same for the four types of novelty: around 0.4 (with a coefficient of variation hovering, in the four cases, around 0.3 ). The relationship between the taxonomy and the generality measure are somewhat more differentiated. The mean generality value for patents classified as originations and refinements is proximately 0.68 and 0.78 respectively (with a median values of about 0.73 and 0.78 ); for the other two novelty types, the mean and median values are both approximately 0.57 (with a median value of 0.5 ). The diversity of technologies a patent draws upon in its prior art, as measured by originality, seems to be indistinguishable and unrelated to a patents technology novelty; however the novelty embedded in an inventions does influence its forward citations. Originations may present information asymmetries that prevent inventors outside that knowledge domain from co-opting a new technology, and refinements may be associated with a later stage in the technological change process that is already highly specialized for particular industries.

The historical record of patenting is chock-full of examples reminding us, however, that there isn't a straightforward relationship between technological novelty, inventive significance and being highly cited. Being the first may open new pathways of invention, but new technologies are rarely sufficiently developed for wide spread diffusion, thus rarely achieve societal impact or commercial success that would lead to relatively higher citation rates. Achieving technological novelty is risky, and just because an invention is very novel does not necessarily make it economically useful. Conversely, there is no reason to believe that inventions 
which are not highly novel cannot have widespread applicability or significant commercial impact.

Consider the following three examples of patents classified as "originations" under our taxonomy. Patent \# 126352, for the improvement of car-axle lubricators and granted in 1872, is one of the first inventions classified as a software patent on account of it involving an algorithmic process for a control system. While highly novel, this patent did not engender much subsequent activity. Patent \#4,504,982, which represents one of the first intraocular lens for permanent implantation into a human eye, a technology only approved by the Federal Drug Administration in 1981, has been cited 117 times (as of the time this paper was written). This is a reassuring story of a highly novel patent being highly cited (and thus, presumably, being found to be useful). But then consider the case of patent \# 7,013,470, for a disk recording-andreproducing device, which is also classified as an origination and which has, up to the time of writing, not been cited. The invention may be very technologically novel, but the market place has not recognized a benefit in utilizing it.

Being highly cited is not a direct consequence of being very novel. As an example, consider patent $\# 5,410,326$, for the universal remote control, which is classified as a novel combination and has been cited 710 times to date. By the time this patent was filed, remote controls were an established technology, and combining a new capability with existing ones greatly reduced risk and produced an economic winner. And being relatively lacking in novelty does not condemn an invention to oblivion. Patent $\# 4,237,224$, for the replication and expression of exogenous genes in microorganisms (the famous, or infamous, Cohen-Boyer biotechnology patent), is classified as a combination yet is considered one of the foundational patents in biotechnology and has been cited 375 times. Patent \#4,683,202, for a process for amplifying 
nucleic acid sequences (the polymerase chain reaction) is classified merely as a "combination" yet has been cited almost 3,000 times since it was granted in 1987. This patent did not cite any prior inventions, but it did combined existing technological capabilities in a novel way (Pisano 2006).

Another citation behemoth is patent $\# 4,723,129$, for the bubble jet printer, which although it did not represent a great leap in technological novelty (it is classified as a "combination"), has been cited 2,331 times. And one of the most useful inventions of the late $19^{\text {th }}$ century, patent \# 575,002 for the Tungsten-filament light bulb, is classified as a combination by the our taxonomy. The replacement of other metals, such as platinum, with a Tungsten filament allowed the invention to achieve great market success but the incandescent light bulb as an artifact had been well established for over 70 years. Highly profitable or societally impactful technological change often derives from refinements of existing technological capabilities rather than developing wholly new technologies (Abernathy and Utterback, 1978; Rosenbloom and Christensen, 1994). Inventions such as Tesla's AC motor (patent \#381,968), the patent for the electrical fixation of atmospheric nitrogen (patent \#1,992,566, for artificial fertilizer) and for the blended winglet (patent \#5,348,253), familiar to most airline passengers who look out their windows and which by reducing wingtip vortices improve the aerodynamic efficiency of airliners' wings, are all classified as refinements under our technological taxonomy.

\section{Technological Novelty and Inventive Significance}

The taxonomy of technological novelty presented here is built upon the procedure followed by the U.S. Patent Office to classify the classify patents' novelty. The taxonomy synthesizes how the Patent Office identifies the technological novelty of patented inventions and builds a graduated notion of novelty: some inventions are classified by a new set of codes while 
others are classified using a set of codes which had already been used. Prima facie, these two cases can be considered as involving different types of technological novelty. The accuracy, nonarbitrariness and usefulness of the taxonomy ultimately rests on the accuracy of the technology codes in identifying technologies. We have presented results showing that, as expected, those patents classified as most novel are characterized, on average, as having fewer prior art citations and being cited more. But how informative is the taxonomy we have built? How closely does the notion of novelty instantiated by the taxonomy match that of students of inventive novelty? Since the taxonomy presented here generates nominal data, how to assess its validity?

There is no agreed-upon definition of "technological novelty", nor are there consensus metrics capturing different levels of inventive novelty against which to compare our taxonomic results against. It would, however, seem reasonable to suppose that patented inventions which have been historically "significant"-because they were technological trailblazers, initiated new industries or became artifacts of widespread daily use-should be classified by our taxonomy as being more novel than other run-of-the-mill patents. We have assembled a list of 175 inventively "significant patents". The list—arbitrary for sure, defensible surely, somewhat idiosyncratic but mostly recognizable by students of invention, verifiable and modifiable by anyone with access to Google-was assembled on the basis of consultation with engineers, scientists, historians, textbooks, magazine articles and internet searches. These patents represent a wide scope of technologies: the flashlight and the universal remote, the foundational patents for biotechnology, the CAT Scan and the MRI, the microwave oven and the martini shaker, the airplane artificial horizon, the electric typewriter, the first diving suit, photovoltaics and metamaterials. The selected patents represent inventive firsts but not all of them spawned technological successors; some went on to become the basis of very profitable commercial ventures while some were 
economic dead ends; some very highly cited by subsequent patents and some were not. The common thread uniting the patents in the list is that the inventions all started technological pathways which affected society, individuals and the economy in a historically significant manner. (The list of patents is presented in Appendix C.)

Table 1 shows the proportion of the 175 "significant" patents accounted for by our four novelty categories and compares these percentages to that of the patent record as a whole. While there is a greater proportion of originations ( $6 \%$ to less than $1 \%)$, inventions representing fully de novo technological functionalities together make for a very small slice of the inventive pie. Combinations of new and existing technologies (novel combinations) have a greater presence in the list of significant patents than in the overall patent record (22\% versus $1 \%$ ). A marked difference between the selected patents and all patents granted by the USPTO is the much reduced role of refinements - as expected since the reuse of existing technologies and combinations of technological functionalities is not likely to generate trailblazing inventions.

The sources of technological novelty instantiated by the patents listed in Appendix C highlight the crucial role of combination in the process of invention. A new type of material highly touted for its non-natural radiation absorbing and refracting properties (metamaterials, patent \# 6791432), the first silicon solar cell (patent \# 2780765), the first microprocessor (patent \# 3757306) and the foundational patents for biotechnology are all instances of novel combinations or combinations. The process of invention overall, and even the generation of significant inventions, at is indeed a combinatorial one.

\section{Discussion}

A formal study of the processes which generate inventions necessitates the identification of countable units of technology. We have shown here that the technology codes used by the 
U.S. Patent Office can be used to identify discrete technological capabilities, define and measure technological novelty, and track the introduction of new technologies. We are therefore able to quantitatively describe the combinatorial process generating most of the inventions recorded by patents granted by the U.S. Patent Office, a process in which there is a limited role for the development of truly new or original technological capabilities.

Inventions are rarely created anew from scratch; instead, much more often they are constructed - put together-from technological components already in existence (Arthur and Polak (2006)). This combinatorial pattern has long been a feature of human innovation and has been identified among hunter gatherers groups (Whallon et al., 2011) and the first urban societies (Algaze, 2014). The role of combinatorics in innovation was highlighted early on by students of innovation — such as Gabriel Tarde in his 1903 book The Laws of Imitation-and recently by studies of scientific production (Uzzi et al., 2013). The taxonomy for classifying the novelty in patented inventions which we have developed is able to reveal, in the modern record of invention, two major sources of technological change which have been operative throughout the history of modern humans, combination of existing capabilities (Mokyr, 1990) and gradual tinkering (Boyd,, Richerson and Heinrich, 2011).

The de novo creation of technologies, which in our taxonomy is identified by the arrival of previously unavailable technological capabilities in the patenting record, has played a very small role as a source of new patents. Patents classified as "novel combinations" (meaning the pairing of existing technologies with newly developed ones) have also been rare. At first glance the implication of these two results is pretty straightforward: truly inventive novelty has been are and is getting rarer. But significant caveats are in order here. The introduction of a new technology codes is not only a reflection of technological developments but also of how quickly, 
and clearly, does the U.S. Patent Office recognize the appearance of a new technological functionality. The release of new technology codes is a laborious process which itself has a laborious consequence (the re-classification of previously granted patents).

We must be careful when gauging the rather sobering unimportance of origination. As long as there is some origination occurring, providing new capabilities as inputs to the inventive system, refinements and recombination can generate inventions at an increasing rate. This feature of the invention process - involving the build-up of a combinatorial "alphabet" allowing for the systematic and even explosive growth of variations and novelty seems to be a general feature of combinatorial processes in nature, culture and technology (McShea and Brandon, 2010). Moreover, we are able to identify the prevalence of "deep" combinations that involve specific technologies drawn from the same general technological domain. The combinatorial process underpinning most of invention does not draw uniformly across the set of existing technologies, on the contrary. Technological combinations are most often formed with similar or related technologies - revealed by combination of codes from within the same technology class. Future research is needed to explore the distinction between deep combinations and combinations that draw upon technology from different classes and families of technologies. Deep combinations may reflect a high level of specialization which the related components are brought together to carry out a single tasks, whereas combinations across classes reflect multiple functionalities be brought together in a product.

Starting in the 1950s the share of new inventions which were the result of recombination began to decline, and concomitantly, the importance of refinements began to increase. Technological refinements of existing technologies have come to dominate the invention landscape. This may be the result of policies that socially and economically that reward 
refinements over other types of invention. Using the language introduced by March (1991), inventors have been increasingly relying on the exploitation (in contrast to the exploration) of the know technology space as the strategy for finding technological novelty. The heightened importance of reusing existing technological capabilities as a source of new inventions coincided with the dramatic increase in the rate of patenting: $44 \%$ of all patents granted to date by the USPTO have been granted since 1990. This increase in patenting activity did not result exclusively, or even primarily, from an increase in inventive capacity but also reflected the increasing role of patents as a signaling device for attracting interest from potential investors and as a means for evaluating the performance of scientists and engineers (Gompers and Lerner, 2001; Jaffe and Lerner, 2006). Under pressure to generate patents in copious amounts, inventive individuals might have turned to refinements as a surer path to obtaining them. But although the rate of origination is declining as a share of inventive activity, even a low rate of origination allows the space of possible technological capabilities to expand at an accelerating rate allowing for a growing set of possible technological combinations.

It is a trite observation to note that all inventions are not created equal, and that many, if not most, patents are economically insignificant. It would seem reasonable to suppose that economically high-impact patents ought to integrate "newer" technologies than those which are not high-impact; however we do not find any straightforward relationship between technological novelty and citations. There are many ways novelty is brought to the invention process and it is necessary to recognize the distinction between arrival of technological novelty and the introduction of technologies or capabilities that reshape economic markets. Our findings provide formal evidence for the claim that technological novelty and economic/social usefulness are not as closely linked as many suppose (see, e.g., David, 1985). 
It is often claimed that the technological changes needed to mitigate serious environmental, sustainability or socioeconomic problems are so large-scaled that incremental technical changes, even over long periods of time, will not be sufficient; successful mitigation change of environmental challenges like climate change requires non-incremental innovation, in addition to accumulated incremental technological change (Nemet, 2009). As nations or firms pour resources into research and develop wide ranging policies motivate non-incremental innovation, how do they measure whether the rate of the sought after non-incremental invention is increasing or slowing? Future analysis may shed insights for policy makers about the type of organizations that are more likely to produce non-incremental innovation like originations and novel combinations. Are there characteristics associated with firms that concentrate more in a particular type of inventive novelty? Are there differences in the characteristics associated with inventors, or inventor teams, associated the different type of inventive novelty? These are all potential research questions that may yield benefits or insights to policy makers, and topics of future research.

There is much that can be studied using the taxonomy of technological novelty presented here. The results above are largely silent on the quality of patents. An obvious research effort is to compare and integrate the insights into the nature of patented inventions obtained from using citations and technology codes. Economic theory, case studies and economic history present often conflicting expectation about the economic costs and benefits of novel invention. In order to understand the consequences for firms or regional economies we must first have a systematic classification of technological novelty to understand the economic consequences of highly novel inventions and long run technological change. With the technological novelty taxonomy presented here we can empirically address questions such as: Are originations primarily 
associated with small organizations (as popular lore would lead us to expect)? Do some firms have a competitive advantage in producing originations and novel combinations, and if so why? What are the temporal dynamics between originations and novel combinations on the one hand, and combinations and refinements on the other, both within firms and industries, and across them? Are the firms that create the originations the same firms that follow it through and also create the refinements, or does another group of imitating cat firms do that? These are questions we seek to address in future research.

We end the discussion by considering a possible limitation of the current research efforts which points to a future research domain. Would a taxonomy of technological novelty built using the World Intellectual Property Organization's (WIPO) “International Patenting Classification" (IPC) or codes from the "Cooperative Patent Classification" (CPC) which is a joint effort between the USPTO and the European Patent Office to harmonize their existing classification systems. The analysis reported here cannot be straightforwardly performed with IPC or CPC codes for two reasons. First the IPC/ CPC code schemas do not take the same approach as the United States Patent Classification (USPC) System when it comes to identifying the units of technology. The IPC and CPC classifications are top down coding systems which do not evolve in response to technologies observed in the inventions brought to the attention of patent examiners; instead the schema is developed and patents are assigned to it. The schema, which is industry-based, is fixed until a new version of the entire schema is developed. Furthermore, the IPC and CPC do not take the same "atomic" approach to technological capabilities. The IPC and CPC were design to be more aligned with industry based definitions of technology than the USPC which implies that the combinatorial inventive process would be largely obscured. Finally, the WIPO and EPOLINE system does not include patent data with consistent set of code 
definitions prior to 1978 . The time series of patents is far shorter, and long run trends cannot be compared across classification schemas. Nonetheless, it would be interesting to perform a similar

analysis on the CPC codes to see if it reveals any trends not observed in the USPC, even if for a shorter period of time.

\section{Acknowledgements}

This work was supported in part by the U.S. Department of Energy (award \# DE - EE0006133).

The authors thank two anonymous reviewers for their many helpful suggestions. The manuscript was greatly improved by the detailed comments made by the editor Ashish Arora. The work reported on here was largely done during research stays at the Santa Fe Institute during the summers of 2013 and 2014 — we gratefully acknowledge the Institute's hospitality. 


\section{Appendix A: Patent Data}

The USPTO makes available data on the technology codes assigned to every patent it has granted in optical disc format (the Cassis Patent Assignments File); the data covers the period from 1790 to the most recent month that data has been archived. The data provided by Cassis file includes the date the patent was granted but not information on the patent filing date. So as to count patents close to the time they were invented we choose to count them in the year they were successfully applied. In order to count patents by application year the patents in the Cassis file have been matched with the patents covered in a database constructed by one of us (Strumsky) using data provided by the United States Patent and Trademark Office (USPTO). This patent database, which covers slightly over 8 million patent records, includes information on filing data for every utility patent granted by the USPTO since 1963.

For utility patents granted prior to 1963 the application year has been obtained from citation records and direct searches. This still left about $13 \%$ of all patents, applied for between 1790 and 1960, without an application year. For these patents the year the patent was granted year was used to replace missing applications years. Prior to the 1980s, the time between the filing of an application and the granting of a patent was significantly less than now (usually taking place within 24 months), and since we use five-year windows to report our results, we don't believe that using granted year for as filing year in those patents introduced any significant bias.

\section{Appendix B: Examples of Technological Novelty in Patents}

The patents described next exemplify the sources of technological novelty discussed in section 3.2. Patent number 4,639,925 (filed for on April 24, 1984 and granted on January 27, 1987) is for a semiconductor laser; this patent is classified by two codes: $372 / 46.013$ and 
372/704. Code 372/46.013 refers to a coherent light generating system in which part of the control system is oxidized when its valance changes form lower to higher, while code 372/704 refers to a semiconductor base structure provided with an etched channel. At the time this patent was published, neither of the two technology codes had been previously seen in the patent record therefore patent 4,639,925 is an example of origination. Patent 7,670,090 (filed on August 12, 2008 and granted on March 2, 2010) for a "system for transporting an airfoil having a root end, a tip end, and a midsection over a railroad, utilizing a first railcar coupled to a second rail car" is another example of a patent resulting from origination: its three codes $(410 / 44,410 / 45,410 / 53)$ had not been previously used to describe an invention.

At the opposite end of the novelty spectrum is patent number 6,286,416 (filed on April 6, 2000 and granted on September 11, 2001) for a Coffee-making apparatus to make coffee and steam for a second time, directly after making a cup of coffee; this patent is categorized with three codes: $99 / 293 ; 99 / 290 ; 323.1$. Code 99/293 refers to an infusion apparatus of the type in which the infusible material is subjected to the action of a vaporized liquid, usually steam; code 99/290 denotes an apparatus for subjecting a material containing an extractable or infusible beverage substance to the action of an extracting fluid which is usually at an elevated temperature; and code 323.1 indicates that the invention involves an electrical system wherein a single electrical source is coupled to a single electrical load circuit and means are provided which control the magnitude or level of the current or voltage. In the case of this coffee-making invention, all three codes used to categorize it had been used in previous patent descriptions, and the binary pairings of the codes have all been used previously to categorize patents. Patent $6,286,416$ is therefore an instance of reusing existing technological capabilities. Another example of reusing existing technological capabilities to create an improved invention is 
provided by patent 2,347,115 (filed in October 18, 1941 and granted in April 18, 1944) for a method to improve the construction of derricks for oil extraction; the patent is described by two codes (52/117 and 52/119). Patent 717,590 (filed for in April 24, 1902 and granted in January 6, 1903) for an improved ship's rudder is another example of an invention which results from using existing technologies to create an improved device. (This patent's description utilizes just two codes: 114/164 and 114/165.)

Patent number 6,408,805 (filed on April 12, 2001) and granted on June 25, 2002 is for a two-stroke cycle engine using a preceding air-layer for scavenging; the patent is categorized by three codes-123/73PP, 123/65P and 123/654-which had been used before in patent classifications, however the three possible pairings of codes have not been seen in a previous patent. This patent is an example of what we term recombination. The patent's three codes refer, respectively, to a two-cycle recompression internal-combustion engines having a cylinder closed at one end and an air-tight casing inclosing the connecting-rod and crank and forming a closed crank-case in open communication with the other end of the cylinder, an internal-combustion engines having a single single-acting working cylinder and a single working piston reciprocating, and a device having an ignition system with an interrupter located in series with the power supply and starting and stopping current flow through primary coil. Patent 6,474,599 (applied for on December 11, 2001 and granted a year later) for an aircraft security system comprising a transparent bullet-proof security chamber interposed between the pilot area and the passenger area, is another example of recombining existing technological capabilities (codified by seven technology codes) to inventing a new device.

Next consider patent number 4,190,105 (filed on September 9, 1977 and granted on February 26, 1980) for a heat exchange coil used in engine radiators. This patent is described by 
three technology codes: 165/179 (an apparatus for transferring heat in which the heat transmitters project from the body wall), 138/38 (using a pipe for changing the direction or rate of flow of a fluid for facilitating the transfer of heat between fluids inside and outside of the pipe), and 165/DIG.536 (an apparatus comprising a non-fluent heat storing mass that in alternation has heat added to it by one fluid stream and removed from it by another). Of these three codes, code 165/DIG.536 had not been used previously to classify a patent. Patent 4,190,105 is therefore an instance of what we term novel combination. Another illustration of a novel recombination is patent 2,155,331 (applied for on December 16, 1938 and granted on April 18, 1939) for a safety apparatus for divers to "ward off creatures of the deep" by means of an electric shock. This invention combines five distinct technological capabilities of which one had not been utilized in prior inventions. 


\begin{tabular}{|c|c|c|c|c|c|c|}
\hline & Patent \# & Year Filed & $\begin{array}{c}\text { Year } \\
\text { Granted }\end{array}$ & Citations & Novelty Classification & Title/Description \\
\hline 1 & 132 & 1837 & 1837 & 0 & Origination & Electric motor \\
\hline 2 & 3633 & 1844 & 1844 & 3 & Novel Combination & Vulcanized rubber \\
\hline 3 & 6281 & 1849 & 1849 & 0 & Novel Combination & Safety Pin \\
\hline 4 & 8080 & 1851 & 1851 & 0 & Origination & Ice machine \\
\hline 5 & 8294 & 1851 & 1851 & 0 & Refinement & Singer sewing machine \\
\hline 6 & 15553 & 1856 & 1856 & 0 & Refinement & Concentrated milk \\
\hline 7 & 19783 & 1858 & 1858 & 3 & Origination & Lead-pencil and eraser \\
\hline 8 & 25532 & 1859 & 1859 & 2 & Origination & Electrical heating surface \\
\hline 9 & 53561 & 1866 & 1866 & 2 & Origination & Social game - first board game \\
\hline 10 & 79265 & 1868 & 1868 & 1 & Novel Combination & Typewriter \\
\hline 11 & 79965 & 1868 & 1868 & 2 & Refinement & Tape measure \\
\hline 12 & 88633 & 1869 & 1869 & 0 & Novel Combination & Celluloid (first synthetic plastic) \\
\hline 13 & 105583 & 1870 & 1870 & 0 & Refinement & Can Opener \\
\hline 14 & 126352 & 1872 & 1872 & 0 & Origination & Improvement in car-axle lubricators (first algorithm) \\
\hline 15 & 174465 & 1876 & 1876 & 6 & Combination & First telephone \\
\hline 16 & 195603 & 1877 & 1877 & 4 & Combination & Stapler \\
\hline 17 & 200521 & 1877 & 1878 & 9 & Origination & Phonograph or speaking machine \\
\hline 18 & 207559 & 1878 & 1878 & 4 & Novel Combination & Qwert keyboard \\
\hline 19 & 220925 & 1879 & 1879 & 0 & Refinement & Flat-bottomed paper bags \\
\hline 20 & 223898 & 1880 & 1880 & 22 & Novel Combination & Light bulb \\
\hline 21 & 271363 & 1882 & 1883 & 0 & Combination & Cash register and indicator \\
\hline 22 & 306577 & 1884 & 1884 & 0 & Refinement & Winshester lever-action repeating rifle. \\
\hline 23 & 355139 & 1885 & 1886 & 1 & Novel Combination & First practical mechanical dishwasher \\
\hline
\end{tabular}




\begin{tabular}{|c|c|c|c|c|c|c|}
\hline 24 & 430804 & 1887 & 1890 & 1 & Novel Combination & Electric adding machine \\
\hline 25 & 425663 & 1889 & 1890 & 0 & Combination & Tractor \\
\hline 26 & 468226 & 1891 & 1892 & 11 & Combination & Twist metal cap \\
\hline 27 & 526130 & 1892 & 1894 & 1 & Novel Combination & Tabulating machine \\
\hline 28 & 520040 & 1893 & 1894 & 2 & Refinement & Mechanical calculator \\
\hline 29 & 544657 & 1895 & 1895 & 4 & Combination & Gas Operated Machine Gun \\
\hline 30 & 549160 & 1895 & 1895 & 0 & Novel Combination & One of the first automobile patents \\
\hline 31 & 558393 & 1895 & 1896 & 3 & Combination & Breakfast cereal \\
\hline 32 & 581901 & 1896 & 1897 & 2 & Combination & Paper clip \\
\hline 33 & 649621 & 1897 & 1900 & 92 & Refinement & $\begin{array}{l}\text { Apparatus for transmission of electrical energy (Tesla's } \\
\text { AC current) }\end{array}$ \\
\hline 34 & 617,592 & 1898 & 1899 & 3 & Novel Combination & Flashlight \\
\hline 35 & 644077 & 1898 & 1900 & 3 & Origination & Aspirin \\
\hline 36 & 678937 & 1900 & 1901 & 3 & Combination & Heavy machine gun \\
\hline 37 & 775134 & 1901 & 1904 & 3 & Novel Combination & Shaving Razor \\
\hline 38 & 775600 & 1903 & 1904 & 0 & Combination & Rotating cement mixer \\
\hline 39 & 821393 & 1903 & 1906 & 22 & Novel Combination & Flying machine \\
\hline 40 & 808897 & 1904 & 1904 & 19 & Combination & Air conditioner \\
\hline 41 & 803684 & 1905 & 1905 & 1 & Combination & Thermionic diode \\
\hline 42 & 841387 & 1906 & 1907 & 4 & Novel Combination & Device for amplifying feeble electrical currents \\
\hline 43 & 879532 & 1907 & 1908 & 0 & Novel Combination & Space Telegraphy \\
\hline 44 & 942699 & 1907 & 1909 & 4 & Combination & Bakelite (first commercially successful plastic) \\
\hline 45 & 998631 & 1907 & 1911 & 1 & Combination & Punch card system used for tabulation (IBM's first patent) \\
\hline 46 & 971501 & 1909 & 1910 & 0 & Novel Combination & Production of ammonia \\
\hline 47 & 1105263 & 1911 & 1914 & 0 & Combination & Portable fire-extinguisher \\
\hline 48 & 1049667 & 1912 & 1914 & 0 & Novel Combination & Manufacture of gasolene \\
\hline 49 & 1203495 & 1913 & 1916 & 4 & Combination & Vacuum tube \\
\hline 50 & 1115674 & 1914 & 1914 & 1 & Origination & Brassiere \\
\hline
\end{tabular}




\begin{tabular}{|c|c|c|c|c|c|c|}
\hline 51 & $1,266,766$ & 1914 & 1918 & 4 & Combination & Cellophane \\
\hline 52 & 1133236 & 1915 & 1915 & 6 & Refinement & Crescent Wrench \\
\hline 53 & 1242872 & 1916 & 1917 & 6 & Combination & Self-serving store \\
\hline 54 & 1394450 & 1920 & 1921 & 2 & Combination & Bread-toaster \\
\hline 55 & 1385682 & 1921 & 1921 & 3 & Novel Combination & First underwater robotics patent \\
\hline 56 & 1475197 & 1921 & 1923 & 2 & Refinement & Food blender \\
\hline 57 & 1392704 & 1921 & 1921 & 2 & Combination & First Athletic Shoe \\
\hline 58 & 1682366 & 1925 & 1928 & 3 & Refinement & Foot-measuring instrument \\
\hline 59 & 1721034 & 1926 & 1929 & 6 & Novel Combination & Polyvinyl chloride (PVC) \\
\hline 60 & 1773980 & 1927 & 1930 & 9 & Novel Combination & Television transmission system \\
\hline 61 & 1800156 & 1927 & 1931 & 37 & Combination & Aerosol spray can \\
\hline 62 & 1867377 & 1928 & 1932 & 2 & Refinement & $\begin{array}{l}\text { Machine for slicing an entire loaf of bread at a single } \\
\text { operation }\end{array}$ \\
\hline 63 & 1821525 & 1929 & 1931 & 12 & Refinement & Hair drier \\
\hline 64 & 1982851 & 1929 & 1934 & 3 & Combination & Artificial horizon \\
\hline 65 & 1929435 & 1930 & 1933 & 4 & Combination & Variable pitch and reversible propeller \\
\hline 66 & 1941066 & 1930 & 1933 & 0 & Refinement & Frequency Modulation (FM) receiver. \\
\hline 67 & 1926039 & 1932 & 1933 & 9 & Novel Combination & Neoprene (first synthetic rubber) \\
\hline 68 & 2013616 & 1932 & 1935 & 30 & Combination & Cocktail shaker \\
\hline 69 & 2032695 & 1934 & 1936 & 15 & Combination & Pocket lighter \\
\hline 70 & 2171765 & 1934 & 1935 & 30 & Novel Combination & Plexiglass \\
\hline 71 & D104289 & 1937 & 1937 & 9 & Refinement & Electric blender \\
\hline 72 & 2196066 & 1938 & 1940 & 20 & Combination & Contact lens \\
\hline 73 & 2196914 & 1938 & 1940 & 7 & Refinement & Shopping cart \\
\hline 74 & 2230654 & 1938 & 1941 & 48 & Combination & Teflon \\
\hline 75 & 2262982 & 1938 & 1941 & 24 & Combination & Toothbrush \\
\hline 76 & 2266828 & 1939 & 1941 & 89 & Combination & Paper cup \\
\hline 77 & 2299328 & 1939 & 1942 & 5 & Combination & Television viewing apparatus \\
\hline
\end{tabular}




\begin{tabular}{|c|c|c|c|c|}
\hline 78 & 2292387 & 1941 & 1942 & 60 \\
\hline 79 & 2442141 & 1945 & 1948 & 13 \\
\hline 80 & 2495429 & 1945 & 1950 & 18 \\
\hline 81 & 2545017 & 1947 & 1951 & 39 \\
\hline 82 & 2547541 & 1948 & 1951 & 7 \\
\hline 83 & 2569347 & 1948 & 1951 & 141 \\
\hline 84 & 2612994 & 1949 & 1952 & 76 \\
\hline 85 & 2642679 & 1949 & 1953 & 19 \\
\hline 86 & 2649759 & 1950 & 1953 & 26 \\
\hline 87 & 2752339 & 1950 & 1956 & 11 \\
\hline 88 & 2663157 & 1951 & 1953 & 8 \\
\hline 89 & D164227 & 1951 & 1951 & 0 \\
\hline 90 & 2833280 & 1952 & 1958 & 10 \\
\hline 91 & $2,825,721$ & 1953 & 1956 & 356 \\
\hline 92 & 2780765 & 1954 & 1957 & 14 \\
\hline 93 & 2892931 & 1955 & 1959 & 5 \\
\hline 94 & 2895584 & 1955 & 1959 & 14 \\
\hline 95 & 2917217 & 1956 & 1959 & 67 \\
\hline 96 & 2912586 & 1957 & 1959 & 20 \\
\hline 97 & 2947611 & 1958 & 1960 & 60 \\
\hline 98 & 3411433 & 1966 & 1968 & 10 \\
\hline 99 & 3481554 & 1966 & 1969 & 22 \\
\hline 100 & $3,541,541$ & 1967 & 1970 & 169 \\
\hline 101 & 3953566 & 1970 & 1976 & 1213 \\
\hline 102 & 3728480 & 1971 & 1973 & 91 \\
\hline 103 & 3757306 & 1971 & 1973 & 99 \\
\hline 104 & 3759161 & 1972 & 1973 & 7 \\
\hline
\end{tabular}

Early technique for spread spectrum communications and frequency hopping

Method for production of penicillin

$\begin{array}{cl}\text { Refinement } & \text { Method for productic } \\ \text { Novel Combination } & \text { Microwave oven }\end{array}$

Combination Hypodermic syringe

Refinement Magic marker

Novel Combination Shockley transistor.

Novel Combination Bar code

Combination The Zamboni

Refinement Cat litter

Combination Cortisone

Combination Picnic cooler

Refinement Fender guitar

Combination Disposable syringe

Novel Combination High-density polyethylene (HDPE)

Combination First patented silicon solar cell

Combination Transistor radio

Combination Selectric typewriter printing head

Combination Styrofoam

Novel Combination Xerographic photocopying machine

Combination Synthetic diamonds

Combination Aluminum foil

Combination Spinning reel

Combination Computer mouse

Combination Gore-tex

Combination First video game

Combination Computing systems cpu

Combination Drip coffeemaker 


\begin{tabular}{|c|c|c|c|c|c|c|}
\hline 105 & 3819921 & 1972 & 1974 & 15 & Combination & Handheld calculator \\
\hline 106 & 3896814 & 1972 & 1975 & 28 & Novel Combination & Collagen based surgery thread \\
\hline 107 & 4259444 & 1972 & 1981 & 25 & Novel Combination & Bacterium capable of breaking down crude oil. \\
\hline 108 & 3821715 & 1973 & 1974 & 135 & Refinement & Intel 4004 microprocessor \\
\hline 109 & 3922552 & 1974 & 1975 & 31 & Combination & CAT-Scan \\
\hline 110 & 4053845 & 1974 & 1977 & 78 & Combination & Optically pumped laser amplifiers \\
\hline 111 & 4004591 & 1975 & 1977 & 43 & Refinement & Modern condom \\
\hline 112 & 4058430 & 1975 & 1977 & 590 & Combination & Atomic layer deposition \\
\hline 113 & 4107288 & 1975 & 1978 & 162 & Novel Combination & Injectable nanoparticles. \\
\hline 114 & 4161436 & 1977 & 1979 & 54 & Combination & Method of energizing a material (laser) \\
\hline 115 & 4405829 & 1977 & 1983 & 1096 & Combination & First public-key cryptography algorithm \\
\hline 116 & 4363877 & 1978 & 1982 & 49 & Combination & Human growth hormone. \\
\hline 117 & 4468464 & 1978 & 1984 & 112 & Combination & Genetic engineering \\
\hline 118 & 4237224 & 1979 & 1980 & 299 & Novel Combination & Genetic engineering \\
\hline 119 & 4309611 & 1980 & 1982 & 6 & Refinement & Scanner for positron emission computed tomography \\
\hline 120 & 4384255 & 1980 & 1983 & 13 & Refinement & Nuclear magnetic resonance systems (MRI) \\
\hline 121 & 4399216 & 1980 & 1983 & 439 & Novel Combination & Simultaneous transformation of two or more genes. \\
\hline 122 & D268584 & 1980 & 1983 & 3 & Refinement & Personal computer \\
\hline 123 & 4476541 & 1982 & 1984 & 5 & Combination & Computer-on-a-chip \\
\hline 124 & 4504982 & 1982 & 1985 & 117 & Origination & $\begin{array}{l}\text { An intraocular lens for permanent implantation into a } \\
\text { human eye }\end{array}$ \\
\hline 125 & 4438032 & 1983 & 1984 & 73 & Combination & Use of cancerous cells for research. \\
\hline 126 & 4558302 & 1983 & 1985 & 313 & Refinement & $\begin{array}{l}\text { High speed data compression and decompression } \\
\text { apparatus and method (.gif) }\end{array}$ \\
\hline 127 & 4634665 & 1983 & 1987 & 162 & Combination & Inserting DNA into eucaryotic cell \\
\hline 128 & 4622557 & 1984 & 1986 & 65 & Combination & GPS device \\
\hline 129 & 4663230 & 1984 & 1987 & 314 & Combination & Fine fibers made of carbon \\
\hline 130 & 4736866 & 1984 & 1988 & 359 & Novel Combination & Genetically modified mouse useful for studying cancer \\
\hline
\end{tabular}




\begin{tabular}{|c|c|c|c|c|c|c|}
\hline 131 & 4740470 & 1984 & 1988 & 14 & Combination & Genetic engineering \\
\hline 132 & 4701745 & 1985 & 1987 & 172 & Refinement & Data compression system \\
\hline 133 & 4733665 & 1985 & 1988 & 2187 & Combination & Cardiac stent device \\
\hline 134 & 4668865 & 1986 & 1987 & 82 & Novel Combination & Scanning tunneling microscope \\
\hline 135 & 4723129 & 1986 & 1988 & 2034 & Combination & Desk jet printer \\
\hline 136 & 4724318 & 1986 & 1988 & 156 & Novel Combination & Atomic force microscope \\
\hline 137 & 5194299 & 1986 & 1993 & 77 & Combination & Post-it note. \\
\hline 138 & 4840175 & 1988 & 1989 & 139 & Refinement & Lasik surgery \\
\hline 139 & 5149636 & 1988 & 1992 & 6 & Combination & Splicing DNA sequences. \\
\hline 140 & 5123902 & 1989 & 1992 & 131 & Combination & Using a laser to cut tissue during surgery \\
\hline 141 & 5184830 & 1989 & 1993 & 166 & Combination & Game boy \\
\hline 142 & 5068916 & 1990 & 1991 & 267 & Combination & Transfer of wireless signal from tower to tower. \\
\hline 143 & 5074437 & 1990 & 1991 & 78 & Combination & Super soaker water gun \\
\hline 144 & 5181200 & 1990 & 1993 & 207 & Combination & Handoff of wirelss signal among link adapters. \\
\hline 145 & 5143745 & 1991 & 1992 & 13 & Combination & $\begin{array}{l}\text { Method to synthesize monomolecular thin film nanotube } \\
\text { coatings }\end{array}$ \\
\hline 146 & 5179017 & 1991 & 1993 & 107 & Refinement & Inserting DNA into a Hamster's ovary cells. \\
\hline 147 & 5193056 & 1991 & 1993 & 313 & Refinement & $\begin{array}{l}\text { Data processing system for hub and spoke financial } \\
\text { services configuration }\end{array}$ \\
\hline 148 & 5225539 & 1991 & 1993 & 549 & Combination & Using recombinant DNA to produce an altered antibody \\
\hline 149 & 5275705 & 1992 & 1994 & 5 & Combination & Fullerenes \\
\hline 150 & 5301348 & 1992 & 1994 & 50 & Novel Combination & Progress bar on computer \\
\hline 151 & 5410326 & 1992 & 1995 & 716 & Novel Combination & Universal remote \\
\hline 152 & 5712327 & 1992 & 1998 & 29 & Combination & Soft contact lens \\
\hline 153 & 5321542 & 1993 & 1994 & 156 & Combination & Fiber optical wireless systems. \\
\hline 154 & 5348253 & 1993 & 1994 & 32 & Refinement & Winglet at tip of airplane wings \\
\hline 155 & 5424054 & 1993 & 1995 & 193 & Novel Combination & Carbon fibers and method for their production \\
\hline 156 & 5462535 & 1994 & 1995 & 41 & Refinement & Insulin pen \\
\hline
\end{tabular}




\begin{tabular}{|c|c|c|c|c|c|c|}
\hline 157 & 6469012 & 1994 & 2002 & 18 & Refinement & Viagra \\
\hline 158 & 5579430 & 1995 & 1996 & 169 & Refinement & Digital encoding process (.mp3) \\
\hline 159 & 5710835 & 1995 & 1998 & 142 & Combination & Storage and retrieval of large digital images (.jpeg) \\
\hline 160 & 5770429 & 1995 & 1998 & 188 & Combination & $\begin{array}{l}\text { Production of high affinity human antibodies from } \\
\text { transgenic mice }\end{array}$ \\
\hline 161 & 5844119 & 1995 & 1998 & 33 & Refinement & Genetic engineering of tobacco plants \\
\hline 162 & 6455275 & 1995 & 2002 & 7 & Refinement & $\begin{array}{l}\text { Insering DNA into eucaryotic cells for producing } \\
\text { proteins. }\end{array}$ \\
\hline 163 & 5843780 & 1996 & 1998 & 218 & Refinement & Primate (including human) embryonic stem cells \\
\hline 164 & 5778814 & 1997 & 1998 & 2 & Refinement & Sunfish sailboat mast design \\
\hline 165 & 5920859 & 1997 & 1999 & 331 & Combination & Google page ranking system \\
\hline 166 & 6235176 & 1997 & 2001 & 36 & Refinement & $\begin{array}{l}\text { Disability insurance for defined contribution pension } \\
\text { plans }\end{array}$ \\
\hline 167 & 6597949 & 2000 & 2003 & 10 & Combination & Modern defibrillator \\
\hline 168 & 6791432 & 2001 & 2004 & 60 & Combination & Left handed composite media (Metamaterials) \\
\hline 169 & 6690134 & 2002 & 2004 & 121 & Combination & Independently mobile mini robot. \\
\hline 170 & 7029178 & 2002 & 2006 & 8 & Refinement & Ziploc \\
\hline 171 & 7260426 & 2002 & 2007 & 74 & Combination & Radition therapy tracking system \\
\hline 172 & 7555727 & 2005 & 2009 & 73 & Combination & Smartphone integration \\
\hline 173 & D591,741 & 2006 & 2009 & 24 & Refinement & The Kindle \\
\hline 174 & 7956847 & 2007 & 2008 & 58 & Refinement & Apple's swipe/multipoint input \\
\hline 175 & 8705177 & 2011 & 2014 & 0 & Refinement & Google glasses \\
\hline
\end{tabular}




\section{References}

Abernathy, W.J., Utterback, J.M. (1978) Patterns of industrial innovation, Technology Review, $80,40-47$.

Albert, M.B., Avery, D., Narin, F., McAllister (1991) Direct validation of citation counts as indicators of industrially important patents, Research Policy, 20, 251-259.

Arthur, W.B. (2007) The structure of invention. Research Policy, 36, 274-287.

Arthur, B. (2009) The Nature of Technology: What It Is and How It Evolves. Free Press, New York.

Auerswald, P, Kauffman, S., Lobo, J., Shell, K. (2000) The production recipes approach to modeling technological innovation: an application to learning by doing. Journal of Economic Dynamics and Control, 24, 389-450.

Basalla, G. (1988) The Evolution of Technology. MIT Press, Cambridge, MA.

Boyd, R., Richerson, P.J., Henrich, J. (2011) The cultural niche: why social learning is essential for human adaptation. Proceedings of the National Academy of Sciences (USA), 108, 10918-10925.

Christensen, C. (1997) The Innovator's Dilemma: When New Technologies Cause Great Firms to Fail. Harvard Business Press, Cambridge, MA.

David, P. (1985) Clio and the Economics of QWERTY, American Economic Review, 75, 332337.

Dahlin, K. B., Behrens, D.M. (2005) When is an invention really radical?: defining and measuring technological radicalness. Research Policy, 34, 717-737.

Fleming, L. 2001. Recombinant uncertainty in technological search, Management Science, 47, 1019-1039.

Fleming, L., Sorenson, O. 2004. Science as a map in technological search, Strategic Management Journal, 25, 909-928.

Gompers, P.A., Lerner, J. 2001. The Money of Invention: How Venture Capital Creates New Wealth. Harvard Business press, Cambridge, MA.

Hall, B.H., Jaffe, A., Trajtenberg, M. 2001. The NBER Patent Citations Data File: Lessons, Insights and Methodological Tools. NBER Working Paper 8498. National Bureau of Economic Research, Cambridge, MA. 
Hall, B.H., Jaffe, A., Trajtenberg, M. 2005. Market value and patent citations, RAND Journal of Economics, 36, 16-38.

Hargadon, A, Sutton, R. 1997. Technology brokering and innovation in a product development firm, Administrative Science Quarterly, 42, 716-749.

Henderson, R. Clark, K. 1990. Architectural innovation: the reconfiguration of existing product technologies and failure of established firms, Administrative Science Quarterly, 35, 9-30.

Jaffe, A., Hall, B.H., Trajtenberg, M. 2005. Market value and patent citations, Rand Journal of Economics, 36, 16-38.

Jaffe, A., Lerner, J. 2006. Innovation and its Discontents: How Our Patent System is Endangering innovation and Progress and What to do About It. Princeton University Press, Princeton.

Lemley, M. 2011. Point of novelty. Northwestern University Law review, 105: 1253-1280.

Lerner, J. 1994. The importance of patent scope: an empirical analysis. The Rand Journal of Economics, 25: 319 - 333.

Levinthal, D. 1997. Adaptation on rugged landscapes, Management Science, 43, 934-950.

McNamee, R.C. (2013) Can't see the forest for the leaves: Similarity and distance measures for hierarchical taxonomies with a patent classification example. Research Policy, 42: 855873.

Marx, M., Strumsky, D., Fleming, L. 2009. Mobility, skills, and the Michigan non-compete Experiment, Management Science, 55, 875-889.

Mokyr, J. 1990. The Lever of Riches: Technological Creativity and Economic Progress. Oxford University Press, New York.

Mott, Lawrence (1997) The Development of the Rudder: A Technological Tale. Arlington (TX): Texas A\&M Press.

Ogburn,W.F. (1950) Social Change. New York: Viking.

Pacey, Arnold (1990) Technology in World Civilization: A Thousand-Year History. Cambridge (MA): the MIT Press.

Pisano, G.P. 2006. Science Business; the promise, the Reality and the Future of Biotech. Harvard Business School Press, Boston.

Purcell, John (1982) From Hand Ax to Laser. New York: Vanguard Press. 
Richerson, .J., Boyd, R. (2004) Not by Genes Alone: How Culture Transformed Human Evolution. Chicago: University of Chicago Press.

Romer, P.M. (2010) What parts of globalization matter for catch-up growth? American Economic Review, 100, 94-98.

Rosenbloom, R. S., Christensen, C.M. 1994. Technological discontinuities, organizational capabilities, and strategic commitments, Industrial and Corporate Change, 3, 655-685.

Rosenberg, N. 1982. Inside the Black Box: Technology and Economics. Cambridge University Press, Cambridge.

Rosenkopf. L., Nerkar, A. (2001) Beyond local search: boundary-spanning, exploration, and impact in the optical disk industry. Strategic Management Journal, 22, 287-306.

Russo, Lucio (2004) The Forgotten Revolution: How Science Was Born in 300 BC and Why it Had to Be Reborn. Berlin: Springer-Verlag.

Sokoloff, K. (1998) Inventive Activity in Early Industrial America: Evidence from Patent Records, 1790-1846. NBER Working Paper 2707.

Strumsky, D., Lobo, J., van der Leeuw, S. 2010. Using patent technology codes to study technological change. Santa Fe Institute Working Paper 10-11-023.

Tarde, G. (1903) The Laws of Imitation. New York: H. Holt and Company.

Trajtenberg, M. 1990. A penny for your quotes: patent citations and the value of innovations, RAND Journal of Economics, 21, 172-187.

Trajtenberg, M., Henderson, R., Jaffe, A. 1997. University versus corporate patents: a window on the basicness of invention, Economics of Innovation and New Technology, 5, 19-50.

Usher, A.P. 1954. A History of Mechanical Inventions. Dover Publication, New York.

Uzzi, B., Mukherjee, S., Stringer, M., Jones, B. (2013) Atypical combination and scientific impact, Science, 342, 468-471.

Von Hippel, E. 1988. The Sources of Innovation. Oxford University Press, New York.

Weitzman, M.L. 1998. Recombinant growth, The Quarterly Journal of Economics, 113, 331360.

Youn, H., Bettencourt, L.M.A., Strumsky, D., Lobo, J. (2014) Invention as a Combinatorial Process: Evidence from U.S. Patents. Santa Fe Institute Working Paper \#14-06-020. 
Table 1. Types of novelty found in selected list of significant patents. (List shown in Appendix C.)

\begin{tabular}{|lccc|}
\hline Novelty Type & N (of 175) & \% (of 175) & $\begin{array}{c}\text { \% of all } \\
\text { patents }\end{array}$ \\
\hline Originations & 10 & $5.7 \%$ & $0.33 \%$ \\
Novel & & & \\
Combination & 38 & $21.7 \%$ & $1.09 \%$ \\
Combination & 84 & $48.0 \%$ & $40.99 \%$ \\
Refinements & 43 & $24.6 \%$ & $57.59 \%$ \\
\hline
\end{tabular}


Figure 1. Distribution of the number of technology codes per patent by 5 year time periods, 1830 - 2014.

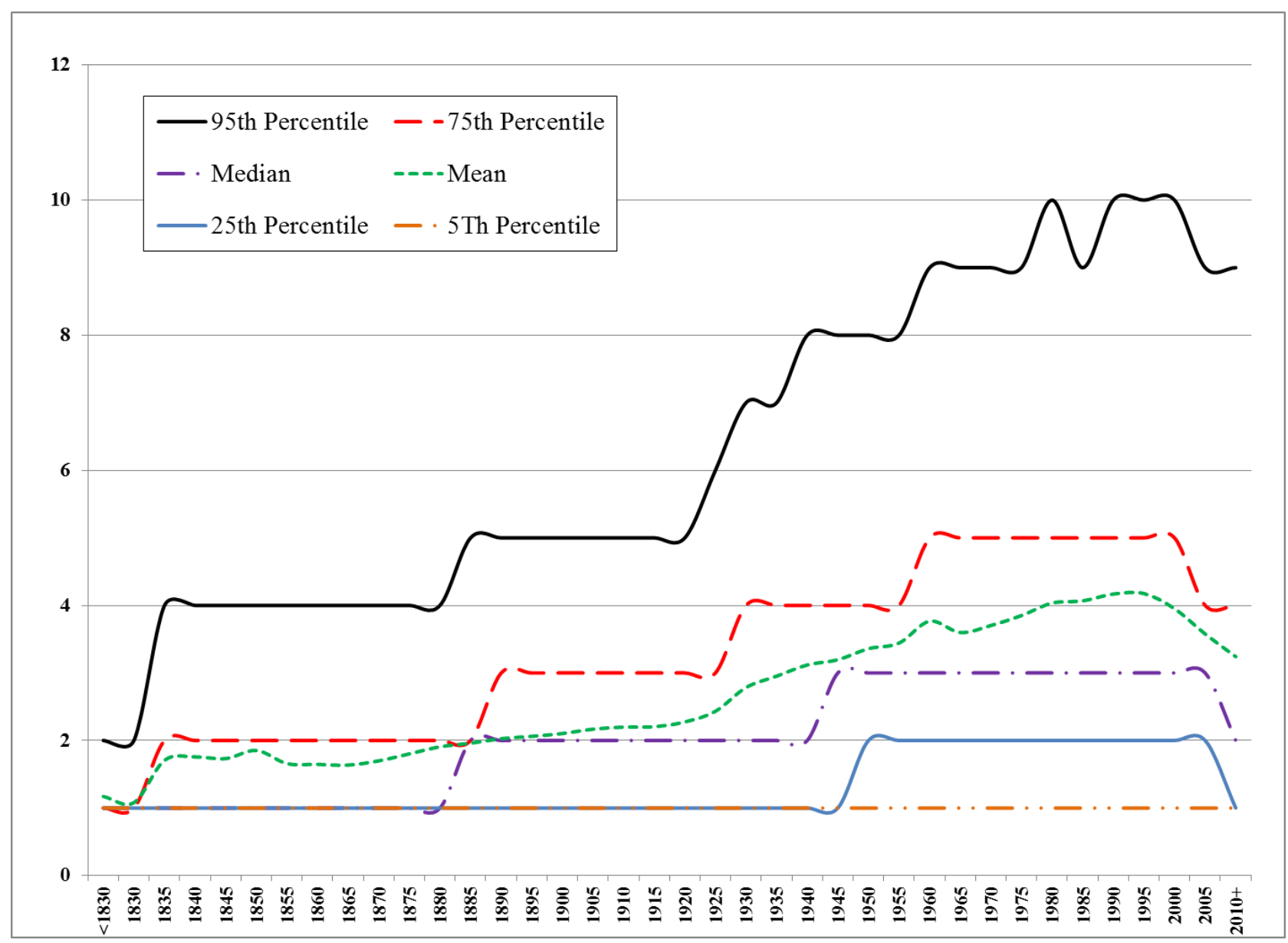


Figure 2. Distribution of patent technology codes n-tuples, all Patents Granted 1830 2014.

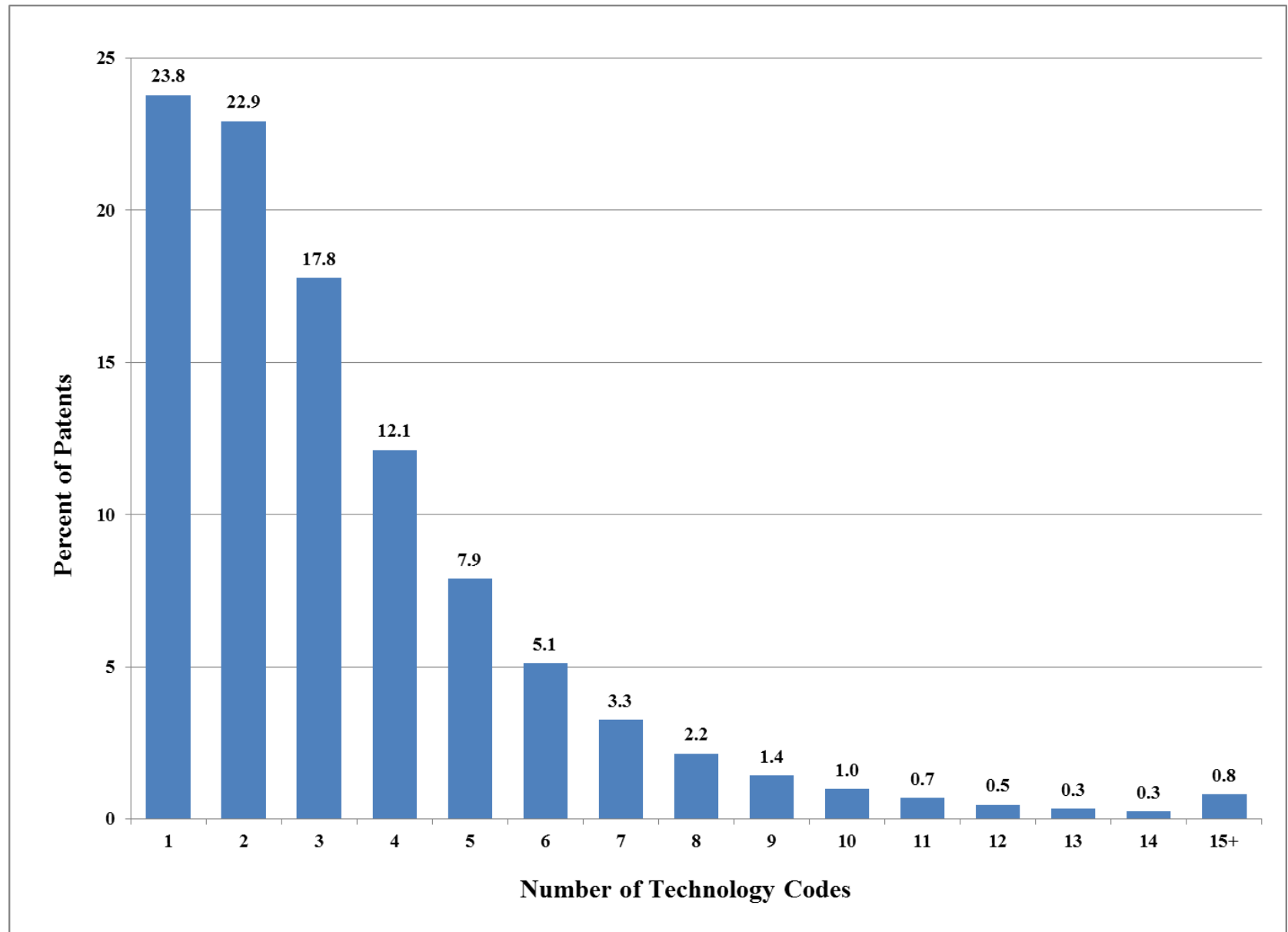


Figure 3. Change over time for the proportion of patents categorized by $n$-tuples (sets of technology codes) of different sizes (the percentages are calculated over five-year windows).

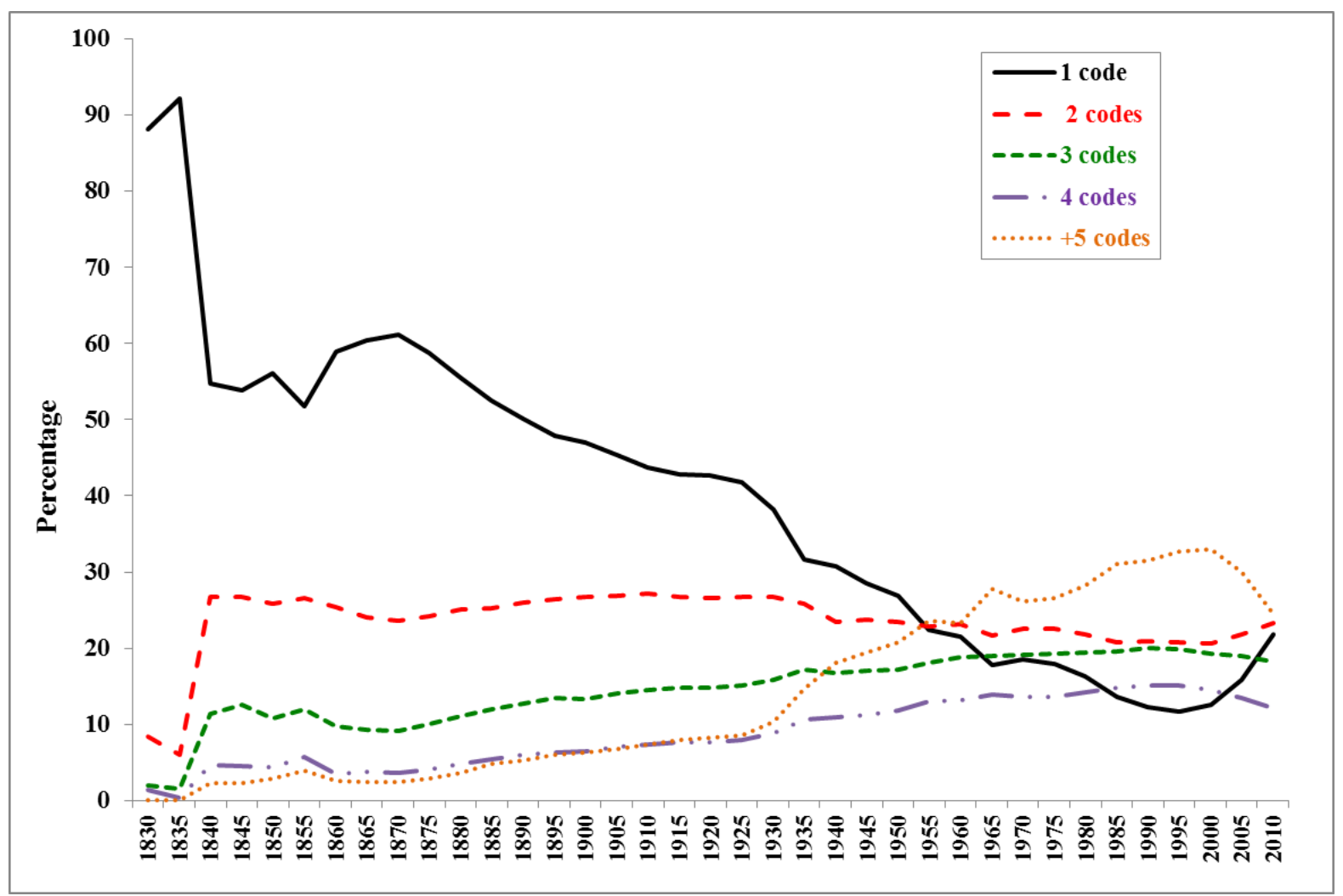


Figure 4. Percentage of differently sized $\boldsymbol{n}$-tuples (sets of technology codes) which are unique (have been used only once to categorize a patent over the period 1830 to 2014).

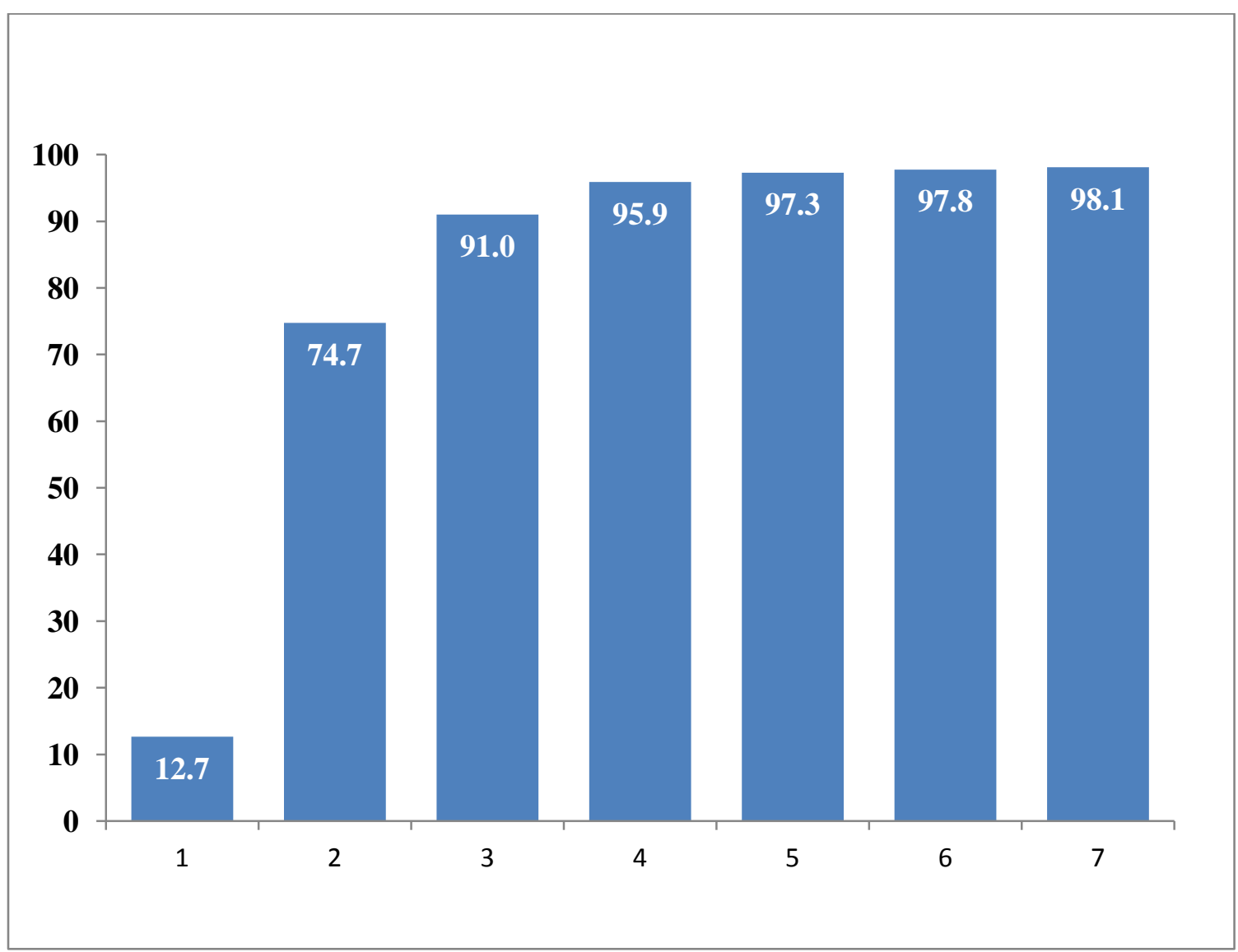


Figure 5. Time series (expressed in natural logarithms for ease of comparison) for the number of total patents and totals for each taxonomy type (data show for five-year windows).

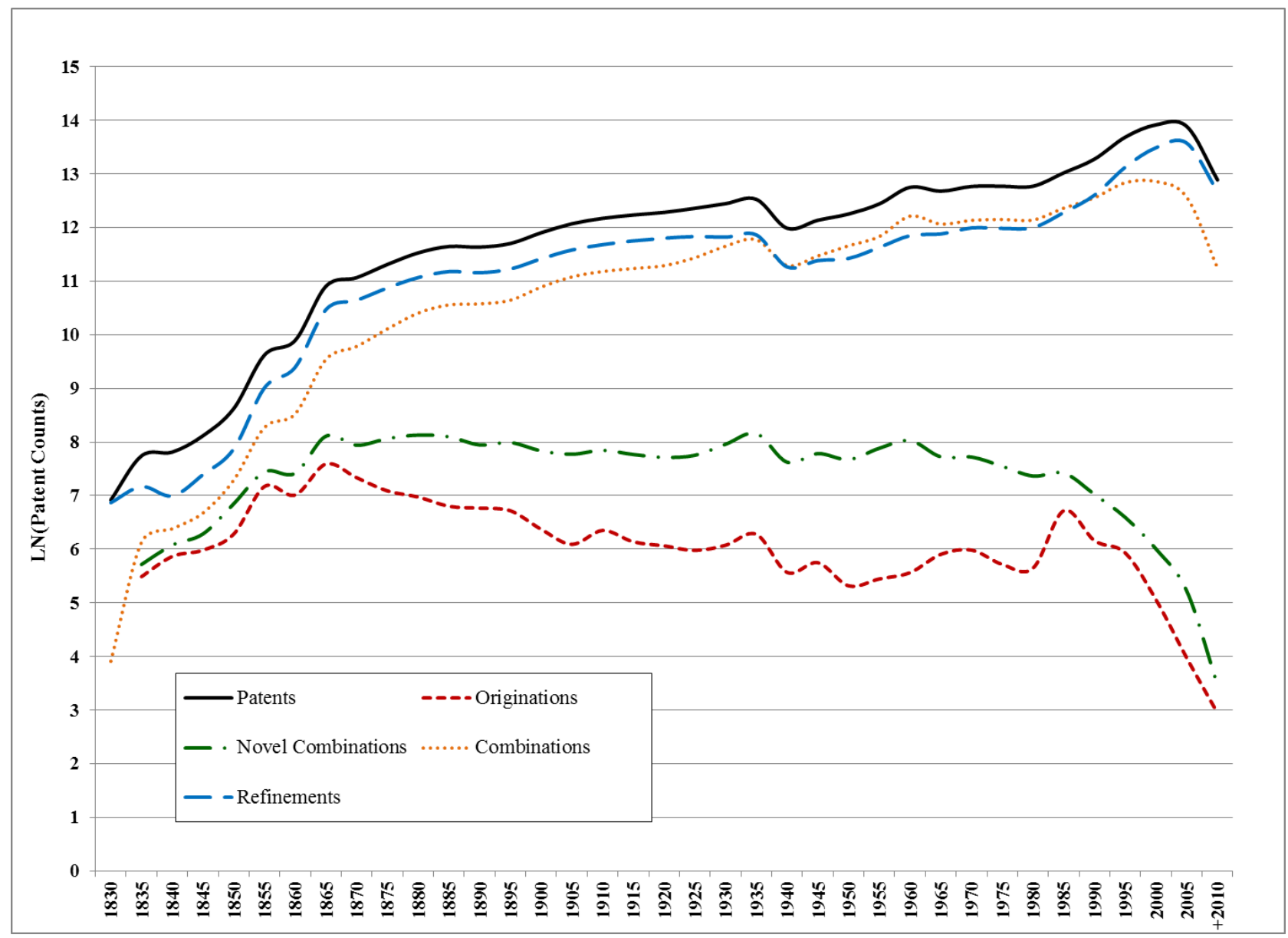


Figure 6. Number of patents (expressed in natural logarithm) granted in each technology novelty category, 1950 and 2010 (in 5-year windows).

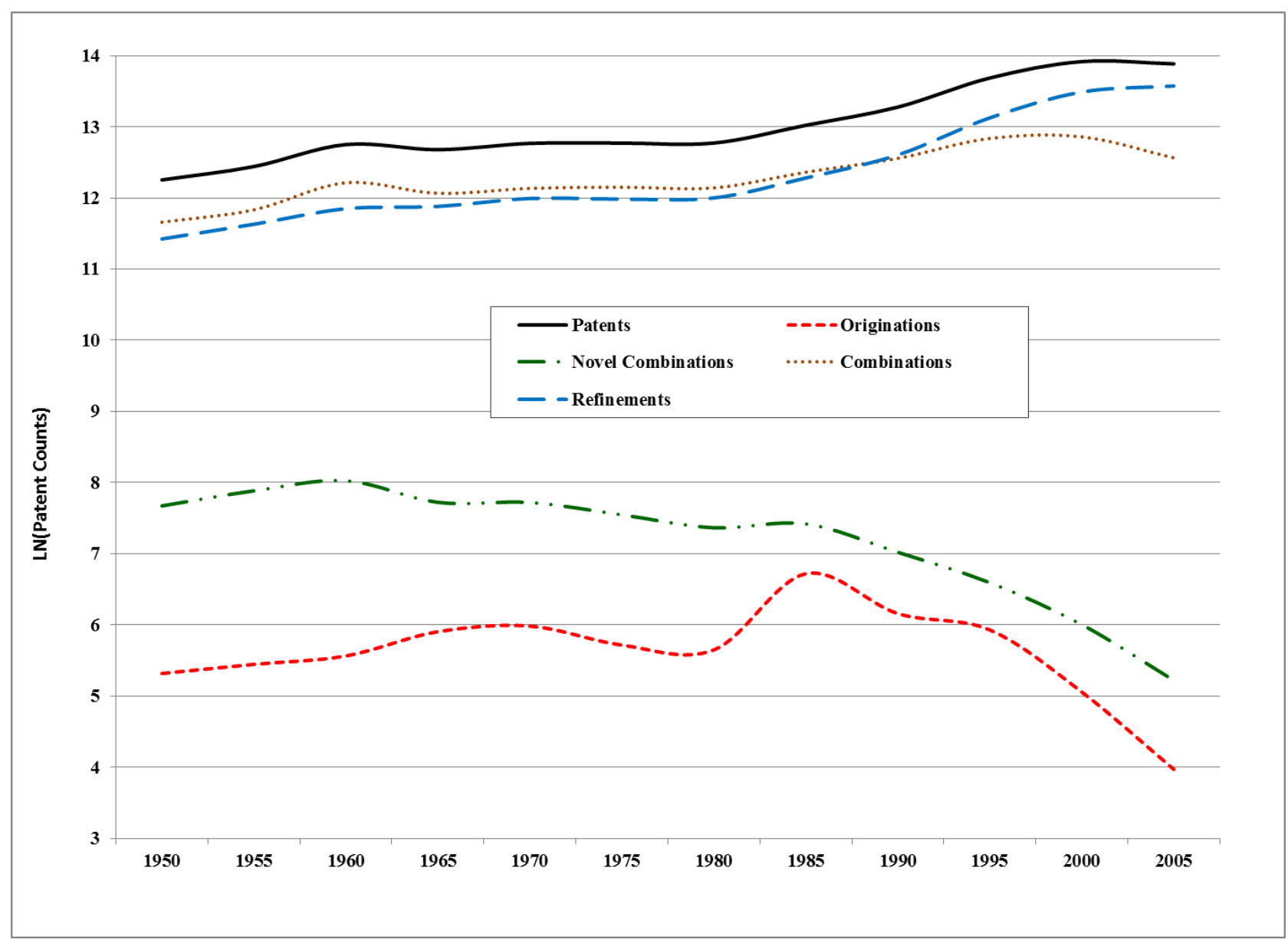


Figure 7. Percentage of new patents, granted during a given time-window, which represent the combination and reuse of existing technological capabilities, as well as the use of new technologies (per 5-year windows)

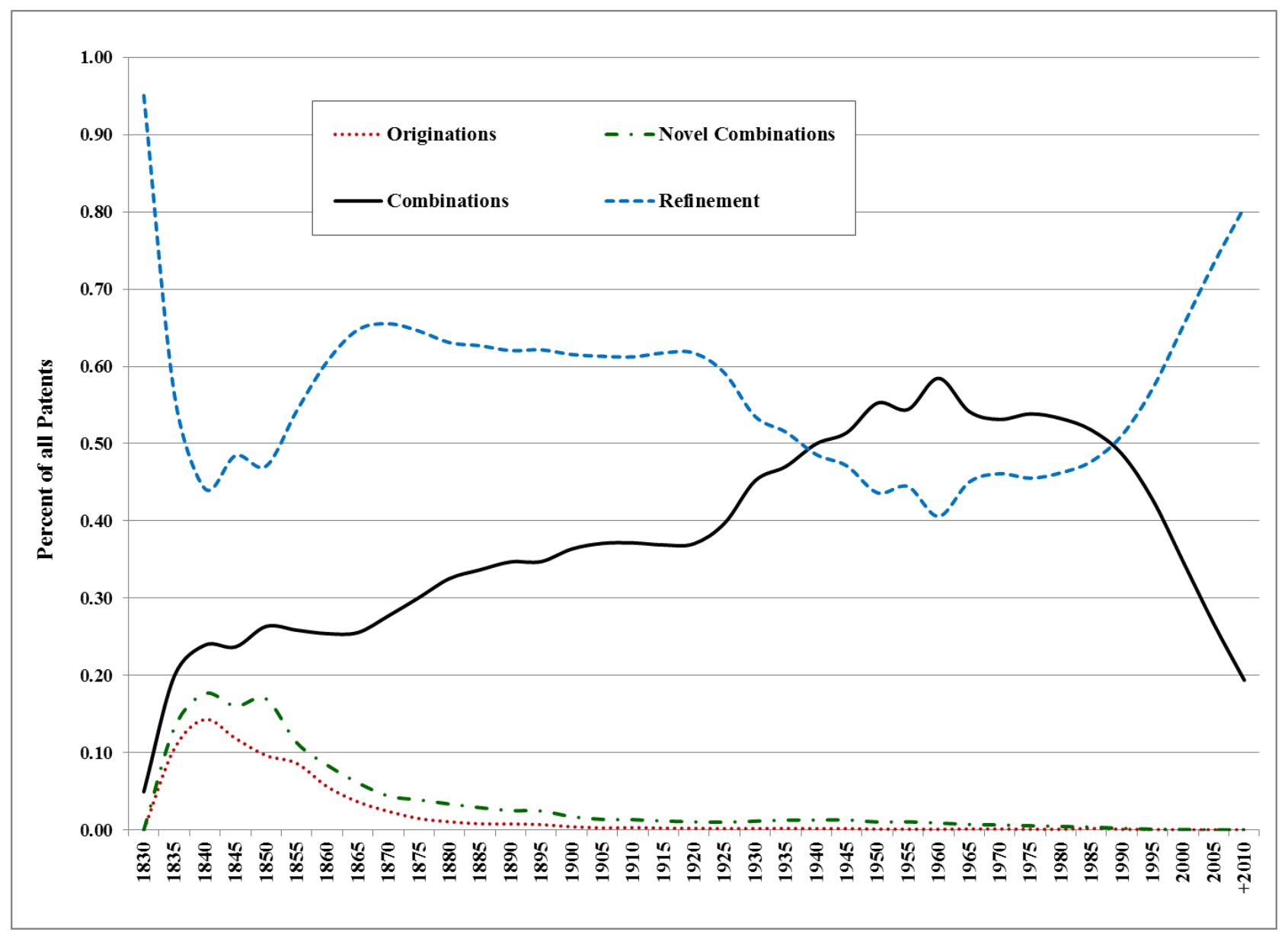


Figure 8. Percentage of patents classified as Originations or Novel Combinations and which have a new code as their "Primary Code", 1830 - 2014 (per 5-year windows).

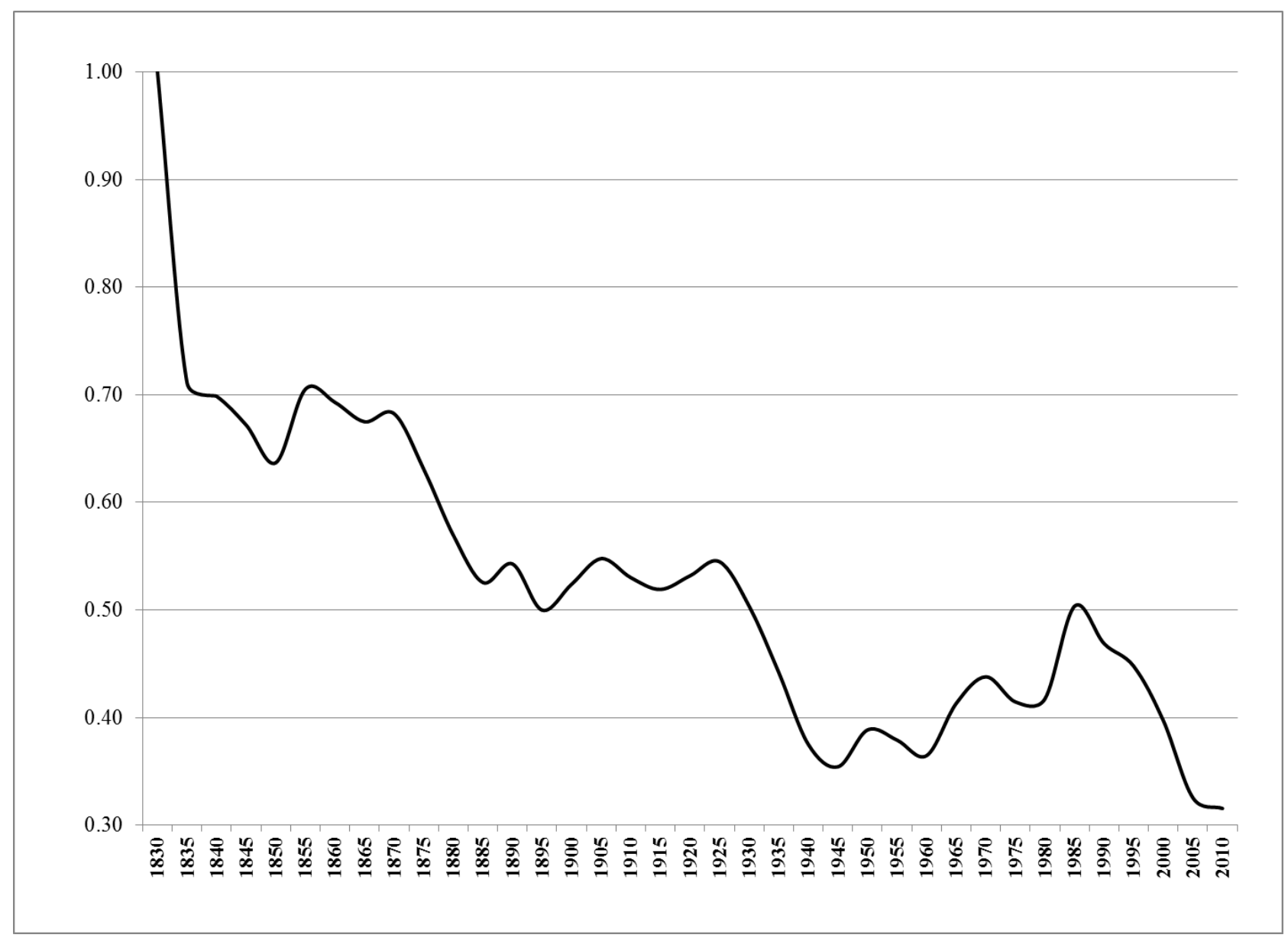


Figure 9. Percent of patents with all their technology codes drawn from the same technology class, 1830-2014 (per 5 year windows).

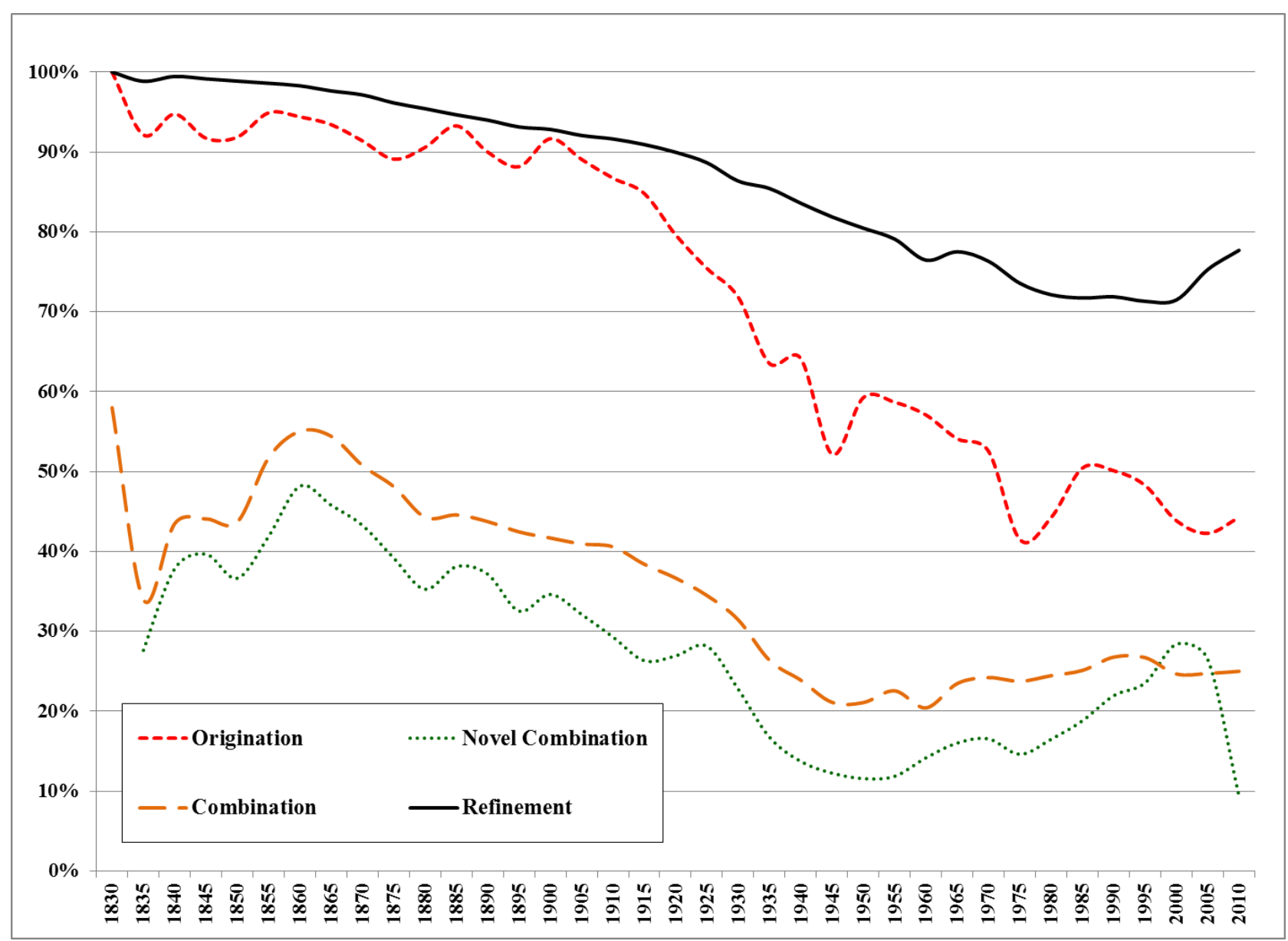


Figure 10. Average Herfindahl index (using technology classes) for each type of patent novelty (per 5 year-windows).

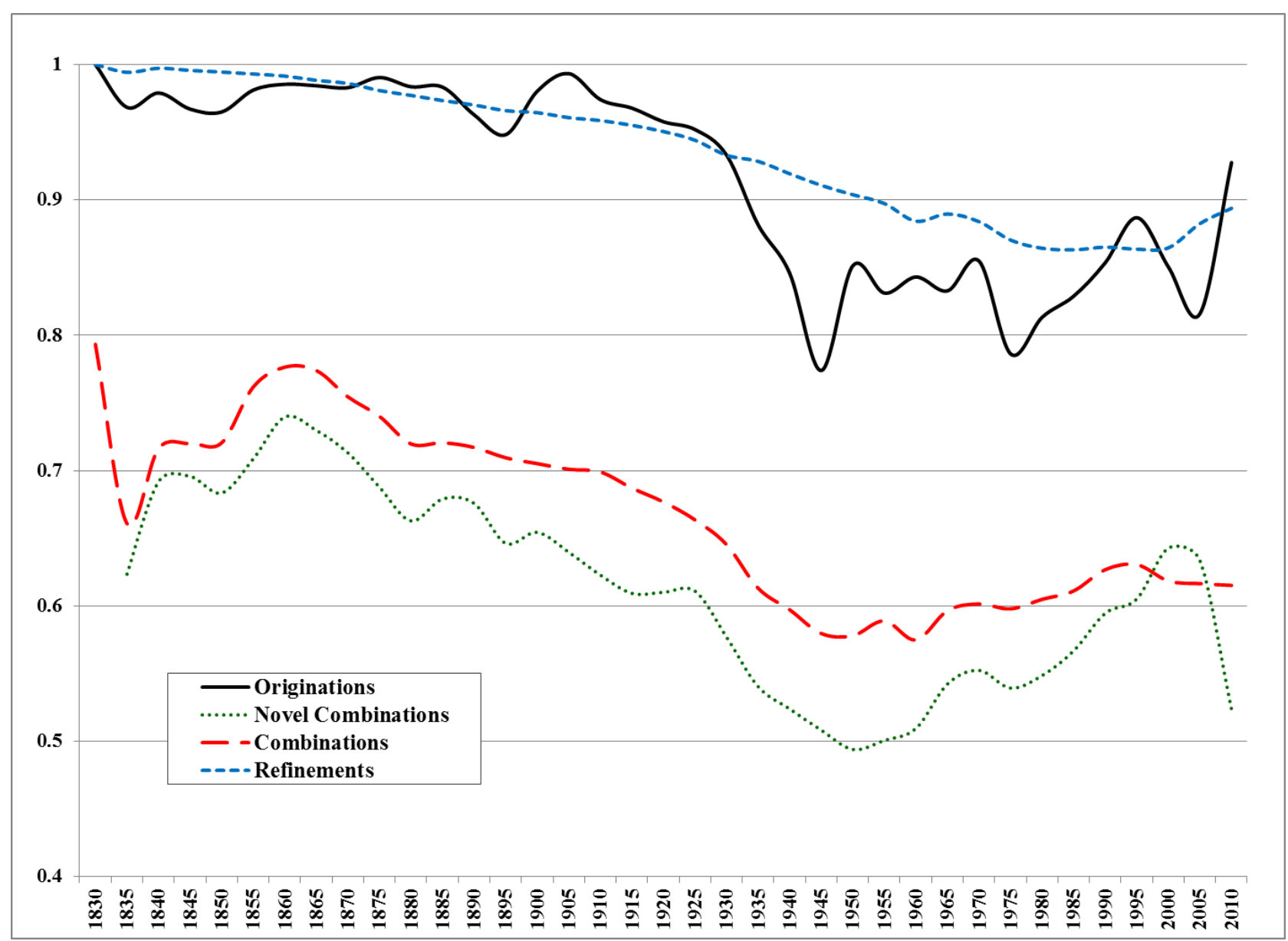


Figure 11. Average citation rates, normalized by grant year cohort and technology class, for each novelty type, $1975-2005$.

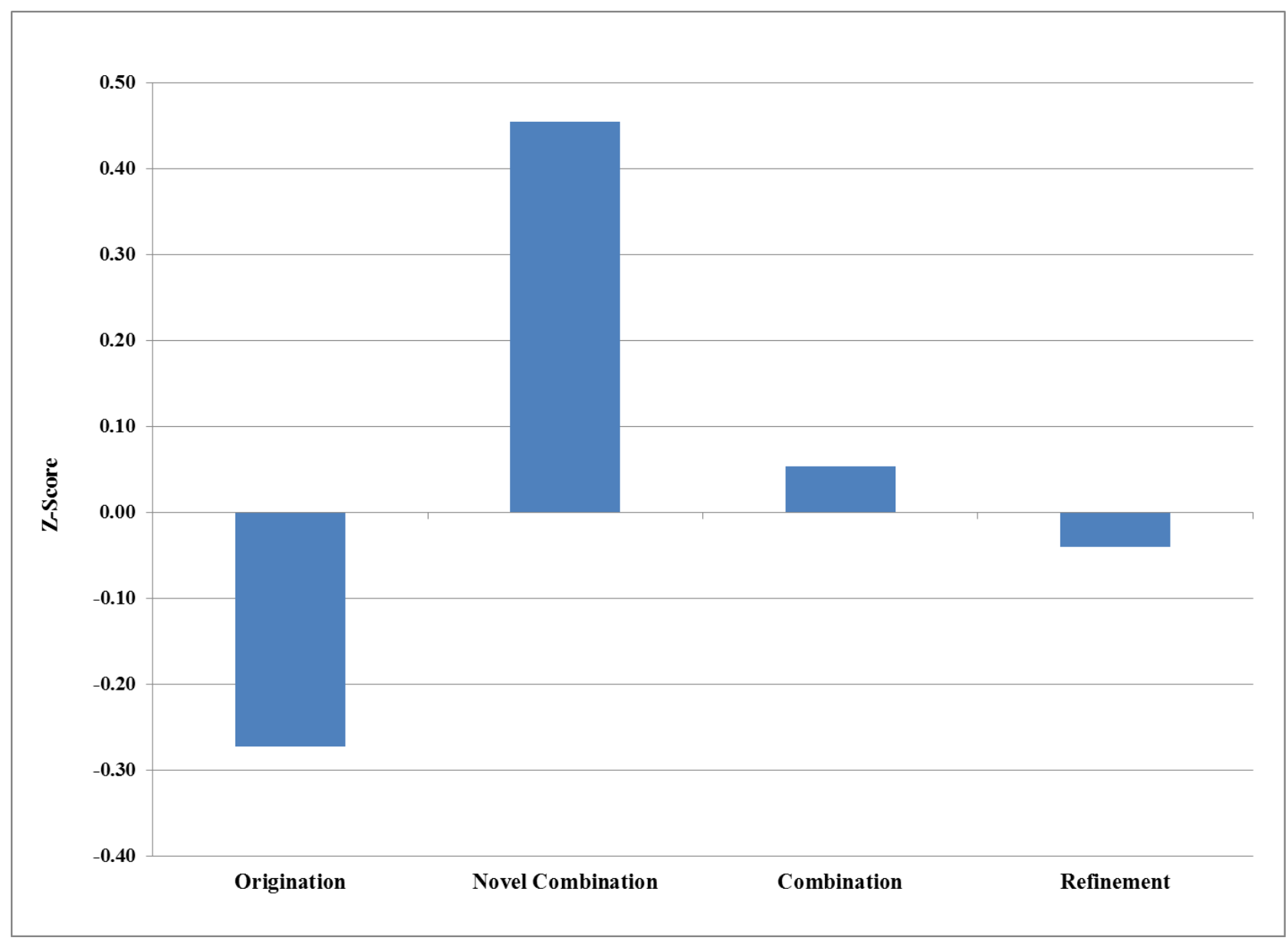

